12

\title{
ASSESSMENT OF TWO LABORATORY DESIGN METHODS FOR CIR MIXTURES WITH BITUMEN EMULSION BASED ON STATIC AND GYRATORY COMPACTION
}

\author{
P. Orosa ${ }^{1,}{ }^{*}$, A. R. Pasandín ${ }^{l}$, and I. Pérez ${ }^{l}$ \\ ${ }^{1}$ Universidade da Coruña, Department of Civil Engineering, E. T. S. I. Caminos, Canales y Puertos, \\ Campus de Elviña s/n, 15071. A Coruña, Spain \\ "Corresponding author. Tel.: +34-981167000. Fax: +34-981167170 \\ E-mail addresses:p.orosa@udc.es (P.Orosa),arodriguezpa@udc.es (A.R. Pasandin), \\ iperez@udc.es (I.Pérez)
}

\begin{abstract}
To expand the body of knowledge regarding cold in-place recycled mixtures, this study presents two different laboratory design methods. The main differences between the methods are the compaction procedures (static and gyratory) and the required strength tests (unconfined compressive strength and indirect tensile strength).

Specimens were manufactured using both methods, with different contents of bitumen emulsion and added water. The effects of adding Portland cement and increasing the compaction energy were also investigated.

The compliance with strength criteria was reviewed, and the optimal bitumen emulsion and water contents were identified. The requirements of the specification based on gyratory compaction proved to be excessively high. A reduction of the values is suggested, and further research is encouraged to allow new benchmarks to be set.
\end{abstract}

Keywords: cold in-place recycling (CIR); asphalt mixture; reclaimed asphalt pavement (RAP); bitumen emulsion; mix design method; gyratory compactor 


\section{Introduction}

Asphalt recycling has increased significantly in recent years and has become one of used pavement rehabilitation techniques is cold in-place recycling $(\mathrm{CIR})$ with bitumen emulsion. This technique consists of milling existing degraded pavement layers and using the resulting material as the main aggregate in a new asphalt mixture. During CIR milling operations, only layers of existing bituminous materials are recycled, reaching depths of 6-12 cm [1]. This recycled bituminous material is known as reclaimed asphalt pavement (RAP) and is usually mixed with bitumen emulsion or foamed bitumen, which acts as the main binder [2]. It is also common for Portland cement or other mineral additives to be used to improve the mechanical properties of this type of mixture [3-6]. Additionally, RAP is frequently used to build base courses and is employed in most low-to-medium-traffic-volume roadways [7].

CIR mixtures have earned global recognition in the last few years, primarily because of their significant environmental and economic benefits [8] compared with traditional methods. CIR mixtures can be manufactured using 100\% milled RAP, which results in the efficient use of resources and construction materials and reduces the amount of transport operations. This technique not only reduces the consumption of aggregates and bitumen, but also reduces the emission of greenhouse gases (i.e. $\mathrm{CO}_{2}$ ) into the atmosphere by $40 \%$, as it is not necessary to heat the mixture [8-12]. Consequently, the fossil-fuel consumption during pavement rehabilitation is minimised, and the technique has a minimal impact on climate change [11,12].

Nevertheless, CIR mixtures require a certain curing period until they reach the desired characteristics. During this period, the mixture loses water, increasing the stiffness and (by extension) the resistant capacity of the initial layer [14]. This is a disadvantage when performing this type of cold rehabilitation $[15,16]$, because it increases the time required to open the road to traffic. Depending on the CIR properties, as well as the environmental conditions (i.e. temperature and humidity), among other factors [17], this curing period can range from 15 to $30 \mathrm{~d}$ and can be even longer $[1,18]$.

Scientific literature worldwide indicates that pavement recycling and rehabilitation has existed since the early $20^{\text {th }}$ century. However, it was not until the mid-1970s that modern CIR-specialised equipment and techniques started to be used $[19,20]$. Although CIR has been used for many years, technical problems remain, such as the standardisation of the mix design, laboratory evaluation methods, implementation, and construction methods. This is why there is not a single, unified regulation for these types of mixtures [21]. Rather than a single standard, different transportation administrations have developed different guidelines and recommendations [22-26]. Additionally, many companies in the pavement recycling sector employ their own manuals [27, 28]

In this context, different specimen compaction methods, curing procedures, testing methods, and specifications are used, depending on the requirements determined by the transportation administrations of various countries [24, 29-35, 38] (Table 1). In recent years, the gyratory compaction method has become increasingly popular, as it has been shown to achieve the closest simulation of field compaction [39]. As indicated by Table 1, this is the method used in countries such Norway, Ireland, and Spain, whereas countries such as the Czech Republic, Germany, and Portugal still employ static pressure compaction in accordance with their standards and research recommendations. The Marshall compaction (impact compaction) is one of the oldest compaction methods and is still widely used. However, it is unsuitable for cold mixtures, because it often results in breakage of the specimens and does not correctly represent the field compaction [36, 37]. 
The lack of a consensus in the curing procedures (period and temperature) can be observed in the different protocols detailed in the different specifications (Table 1). We can initially differentiate the protocols involving air curing (generally under room conditions for a long period) from the protocols involving accelerated curing at an elevated temperature. Regarding air curing, Graziani et al. [16] concluded that after 28 $\mathrm{d}$, the water evaporation process is practically complete. In fact, this curing period appears in specifications of the UK, Czech Republic, Finland, etc. (Table 1). Accelerated curing is also aimed at representing the long-term equilibrium moisture content; however, in this case, the temperatures usually range from 40 to $60 \stackrel{\circ}{ } \mathrm{C}$, and the period is $16-72 \mathrm{~h}$.

11 Finally, with regard to the strength and water sensitivity tests used for cold mixtures, the indirect tensile strength (ITS) test is currently the most widely used test (Table 1). Compression tests are also frequently applied, albeit to a lesser extent (Table 1). The dimensions of the specimens produced are usually based on the required tests, but they are also limited by the maximum sizes of the RAP used.

While most of the manuals and guidelines for CIR set targets for the density (i.e. related to the Modified Proctor test result), they do not limit the air-void content (as is the case for HMA mixtures). However, a few specifications and technical references indicate that the air-void content of laboratory CIR specimens usually ranges from $8 \%$ to $15 \%[6,7,18,21,30,31,34,39]$. Regarding the field compaction of CIR mixtures, technical reports indicate that a well-compacted mixture generally has an air-void content between $12 \%$ and $15 \%$, and the density ranges from 2000 to $2100 \mathrm{~kg} / \mathrm{m}^{3}$ [4043]. These ranges are not fixed; they can change owing to the heterogeneity of the RAP and its sources.

In Spain in particular, the applicable standard is known as PG-4 [1, 45]. In 2017, the PG-4 based on Circular Order 40/2017 [1] (i.e. the current PG-4) replaced the PG-4 based on Circular Order 8/2001 [45] (i.e. the former PG-4). This updated specification introduced new requirements for the design and evaluation of CIR mixtures and included construction and implementation techniques, as well as laboratory manufacturing, curing, and testing procedures. The current PG-4 regulation also included changes to the CIR sample compaction method (i.e. introducing gyratory instead of static compaction) and tests used to determine the mechanical strength and water sensitivity (i.e. the ITS instead of the unconfined compressive strength (UCS)). These substantial changes to the design procedure for CIR mixtures and their impact on pavement recycling in Spain motivated the present comparative study. 


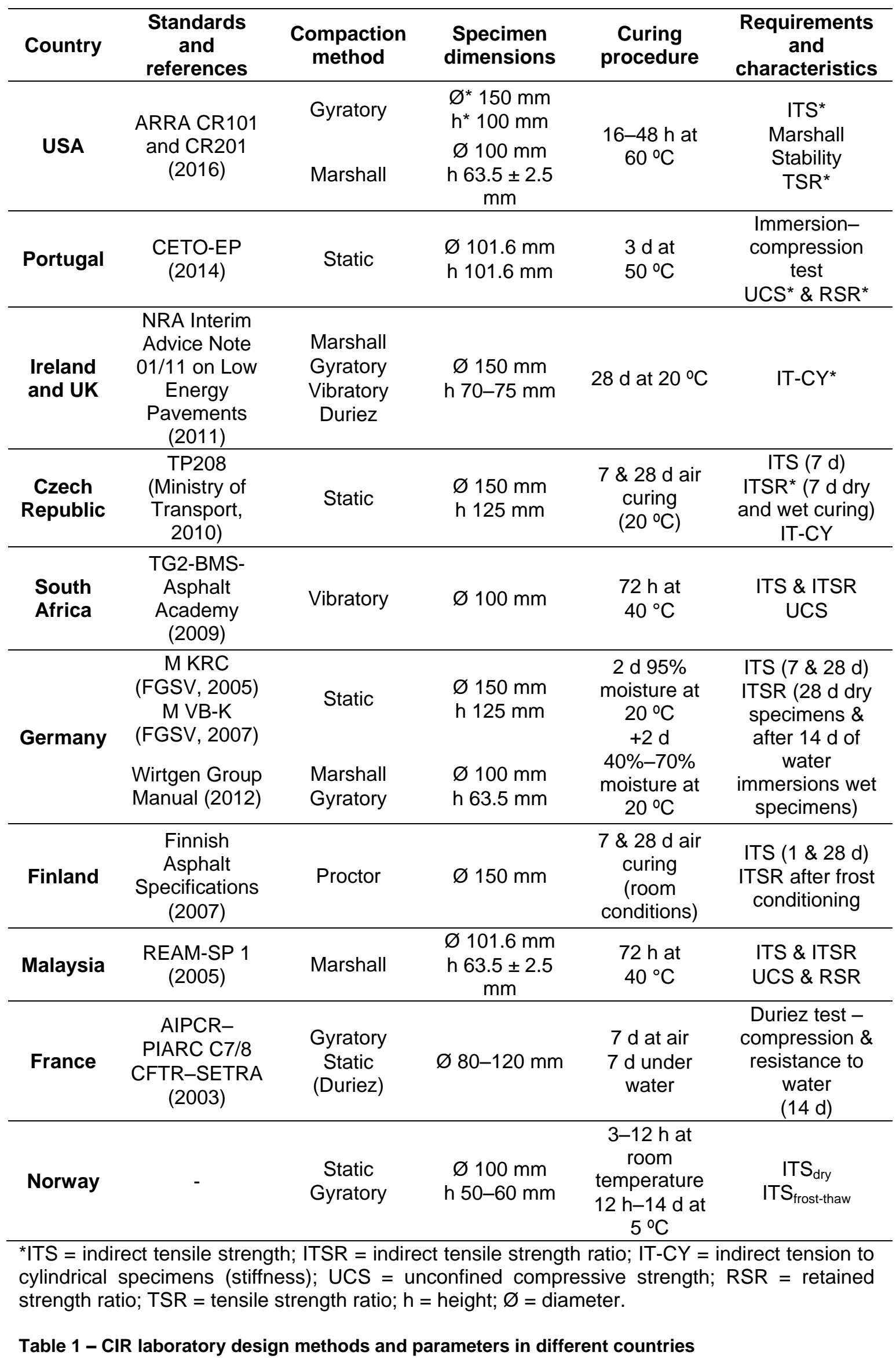




\section{Motivation}

2 Because of the modification of the aforementioned Spanish specification, CIR materials 3 that could previously be used according to the former specification [45] are now no 4 longer suitable according to the current one [1]. The current specification was 5 established in 2017, and there have been no validated studies or reports on which it is 6 based, to the authors' knowledge. Recent practical experience has indicated that the 7 implementation of road works with CIR mixes with bitumen emulsions satisfying the 8 current design criteria [1] is not possible.

9 Thus, after corroborating this fact, different administrations and contractors within the 10 highway sector in Spain considered that the existing specification should be reviewed. 11 In this context, extensive studies on CIR mixtures must be performed for establishing 12 valid new design criteria.

\section{3. Aims and scope}

14 In view of the necessary revision of the current Spanish specification for CIR [1], it was decided to conduct this study. The primary objective of the study was to determine and analyse the differences between the two methods employed in Spain for the design of $\mathrm{CIR}$, which are contained in the current and former $\mathrm{PG}-4$ regulations:

- PG-4 from Circular Order 8/2001 [45].

- PG-4 from Circular Order 40/2017 [1].

To perform this comparative study, CIR specimens were manufactured in accordance with both specifications, with different contents of residual binder and added water, which ranged from $1.50 \%$ to $5.25 \%$ and from $0.00 \%$ to $2.75 \%$, respectively. After a specimen curing process and testing of the strength and water sensitivity, the compliance of the specimens with the requirements of each specification was checked, and the optimum residual binder and added-water contents (AWCs) in each case were determined.

Finally, for the mixtures manufactured according to the current PG-4 [1] (and in view of the present problems with the design criteria of this specification), the effects of the variations of different parameters (AWC, added Portland cement content, number of compaction gyrations) were evaluated. 


\section{Materials and methods}

\subsection{Materials}

\subsubsection{RAP}

RAP milled from the upper portion of pre-existing asphalt road pavements was employed in this study. A local contractor supplied the RAP.

The Spanish design methods used in this study require the size distribution of the RAP to be within certain gradation limits for the RAP to be used in CIR mixtures. In this regard, the black granulometry of the RAP was determined according to EN-933-1 [46]. As shown in Figure 1, the sieve size distribution corresponds to gradation range RE1 according to the former PG-4 standard [45] and to gradation range RE2 according to the current PG-4 standard [1]. While the two gradation limits are similar with regard to the smallest sieve sizes, the larger sieve sizes differ slightly. Thus, the gradation limits of RE2 (current PG-4) are moved upward (made more restrictive with regard to the coarse fraction) for these particle sizes.

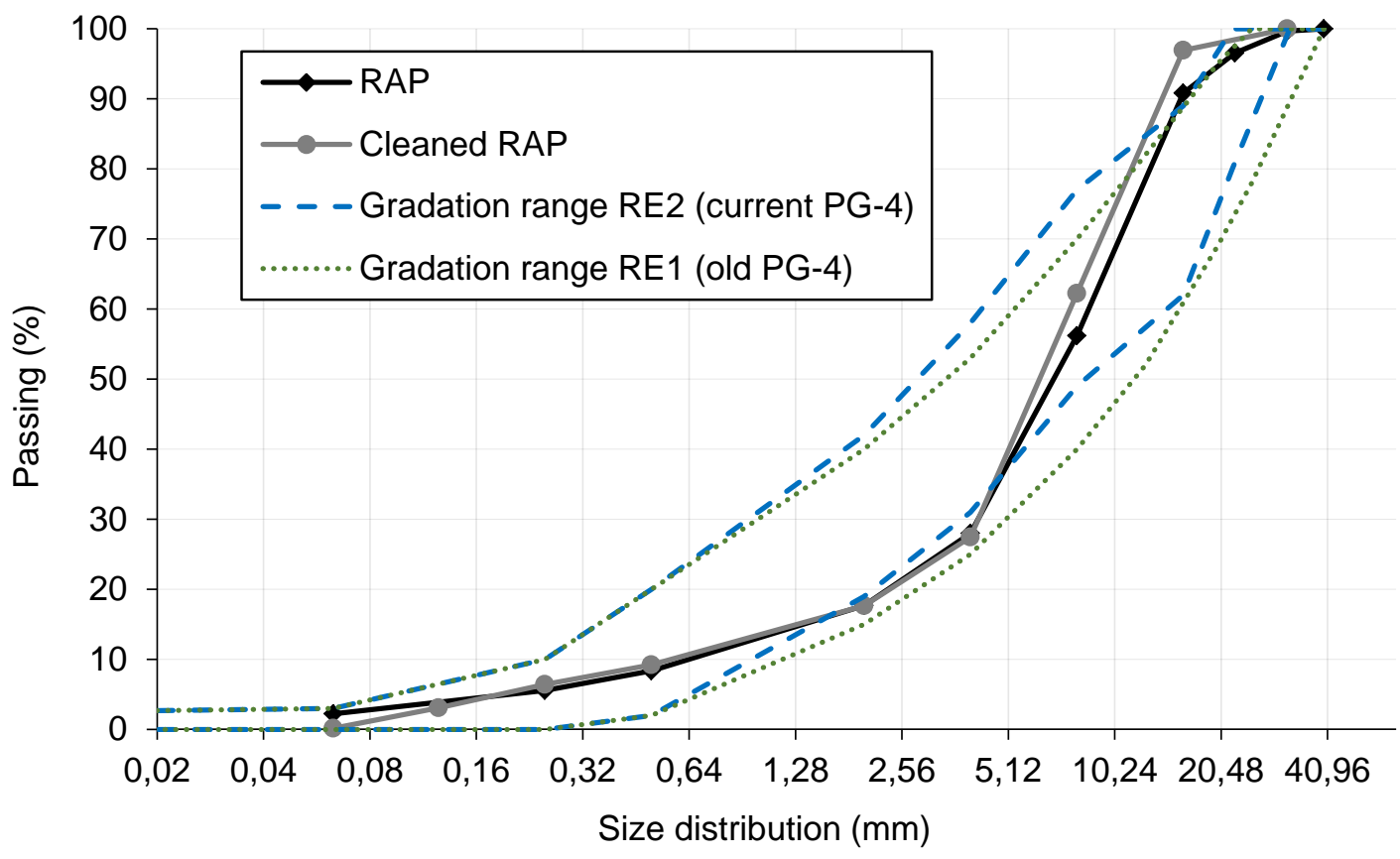

Figure 1 - RAP gradation compared with the PG-4 orders.

As shown in Figure 1, the RAP size distribution did not fit exactly into any of the previously defined gradation limits. Nevertheless, it can be observed that the best fit occurred in the case of gradation range RE1 for the former PG-4 [45]. A comparison of the granulometric distribution of the extracted aggregate (i.e. cleaned RAP) with that of the original RAP is also presented in Figure 1. As expected, the grain-size distribution of the cleaned RAP for the largest sieve sizes was finer than that of the original RAP.

The bulk specific density of the RAP was $2.56 \mathrm{~g} / \mathrm{cm}^{3}$, which was obtained in accordance with EN 1097-6 [47]. The residual binder content (BC) was 7.81\% (relative to the weight of the aggregate) and was obtained in accordance with the Spanish standard NLT-164/90 [48]. The penetration and softening point values of the recovered bitumen are presented in Table 2. As shown, the content of recovered bitumen in the RAP was above average. This binder content was high because the RAP was obtained via the milling of superficial wearing layers, which typically have higher contents of bitumen. 
The bitumen emulsion used was C60B5 REC, which is a cationic slow-setting emulsion with a bitumen content of $60 \%$ for use in CIR mixtures [49]. A Spanish petroleum company supplied the bitumen emulsion. The penetration and softening point values of the residual bitumen used to manufacture the bitumen emulsion are presented in Table 2.

\begin{tabular}{cccc}
\hline \multirow{2}{*}{ Property } & \multirow{2}{*}{ EN standard } & \multicolumn{2}{c}{ Test results } \\
\cline { 3 - 4 } & & Recovered bitumen & Residual bitumen \\
\hline Penetration $\left(\mathbf{1 0}^{-1} \mathbf{~ m m}\right)$ & 1426 & 20.32 & 170.00 \\
Softening point $\left({ }^{\circ} \mathbf{C}\right)$ & 1427 & 64.40 & 36.50 \\
\hline
\end{tabular}

Table 2 - Properties of recovered and residual bitumen

In this study, different contents of residual binder and bitumen emulsion were used (see Tables 3 and 4). Additionally, the water content was varied to maintain the determined optimum fluid content (OFC).

\subsubsection{Portland cement}

Grey Portland cement CEM II/B-M (V-L) 32.5 was used as an additional mineral filler in one of the studied mixtures. The current PG-4 [1] specification allows Portland cement to be added to a CIR mixture to improve the adhesion and strength of the mixture. Up to $1 \%$ of the RAP content (by weight) can be added.

The specific gravity of the cement was equal to $3.10 \mathrm{~g} / \mathrm{cm}^{3}$. This type of cement was selected because it is commonly used as an additive in CIR mixtures [3,49].

\subsection{Methods}

3.2.1. Aggregate coating tests

EN 7151 [50] was followed to identify the optimal aggregate coating. The mixing procedure was divided into two phases. First, the RAP and added water were mixed for $60 \mathrm{~s}$. Then, the bituminous emulsion was added, and additional mixing was performed. Some studies have recommended that the bitumen emulsion mixing time for CIR mixtures should not exceed $120 \mathrm{~s}$, to avoid breaking the emulsion [51]. However, to ensure adequate coating of the RAP, this mixing time should not be less than $60 \mathrm{~s}$ [51]. In this regard, two different bitumen emulsion mixing times were tested (60 and $90 \mathrm{~s}$ ), with each employing different binder and AWCs.

Therefore, the total mixing times used for the coating tests were as follows.

- $\quad$ Mixing time $1=60 \mathrm{~s}+60 \mathrm{~s}=120 \mathrm{~s}$

- Mixing time $2=60 \mathrm{~s}+90 \mathrm{~s}=150 \mathrm{~s}$

\subsubsection{OFC and Modified Proctor test}

The OFC was defined as the water content that provided the maximum dry density in the mixtures. This value was the result of the Modified Proctor tests, which were conducted in accordance with EN 103-501 [52].

To begin, the RAP was heated to $60{ }^{\circ} \mathrm{C}$ for $24 \mathrm{~h}$ to dry it completely and homogenise the water content of the samples in accordance with the PG-4 specifications. After the sample was returned to room temperature $\left(20^{\circ} \mathrm{C}\right)$, the RAP was divided into six samples. The dried RAP samples were mixed with different amounts of water (ranging from $1.50 \%$ to $7.50 \%$, and from $3.00 \%$ to $10.50 \%$ in the cases where $1.00 \%$ Portland cement was added to the RAP). The dry density-water content curves of the different samples were obtained to estimate the OFC corresponding to the maximum dry density. 
2 The AWC was calculated using the following equations.

- Circular Order 8/2001 [45]: \% AWC = \% OFC - 0.5\% - \% EC

Equation 1

- Circular Order 40/2017 [1]: \% AWC = \% OFC - 0.5\% - \% BC Equation 2

In the former PG-4 [45] specification, the AWC was calculated by subtracting the percentage of the bitumen emulsion content (EC) and an additional $0.5 \%$ from the OFC value obtained from the Modified Proctor test [52]. In the current PG-4 [1] specification, the $B C$ is subtracted instead of the EC.

9 The mixing water content in the current PG-4 [1] specification (Equation 2) is higher 10 than that in the former PG-4. This is because the percentage corresponding to the BC 11 is lower than that corresponding to the EC.

12 In other studies, the water content for CIR mixtures was determined using Equation 1. In these cases, the bitumen emulsion was considered to act as a lubricant during compaction; consequently, the total fluid content was considered to be the total of the added water and the bitumen emulsion $[51,53,54]$.

\subsubsection{Static compaction}

Taking into account the former PG-4 [45], cylindrical samples with a diameter of 101.6 $\mathrm{mm}$ and a height of $101.6 \mathrm{~mm}$ were manufactured with five different BCs (Table 3).

The specimens from the static group (SG) were compacted by applying a static axial pressure of $21 \mathrm{MPa}$ for $2 \mathrm{~min}$ after a preload period of $1 \mathrm{~min}$ at $1 \mathrm{MPa}$, in accordance with the Spanish standard described in NLT-161 [55] (Figure 2a), which is derived from the French Duriez test (NF P98-251) [56] and is widely used in Spain.

\begin{tabular}{|c|c|c|c|c|c|c|}
\hline Group Name & BC & EC & & AWC & $\begin{array}{c}\text { Portland } \\
\text { Cement }\end{array}$ & $\begin{array}{c}\text { № of } \\
\text { specimens }\end{array}$ \\
\hline \multirow{5}{*}{ SG } & $1.50 \%$ & $2.50 \%$ & \multirow{5}{*}{$\dot{\overline{\dot{\varphi}}}$} & $2.75 \%$ & \multirow{5}{*}{$0.00 \%$} & 10 \\
\hline & $1.75 \%$ & $2.92 \%$ & & $2.33 \%$ & & 10 \\
\hline & $2.00 \%$ & $3.33 \%$ & & $1.92 \%$ & & 10 \\
\hline & $2.25 \%$ & $3.75 \%$ & & $1.50 \%$ & & 10 \\
\hline & $2.50 \%$ & $4.17 \%$ & & $1.08 \%$ & & 10 \\
\hline
\end{tabular}


2 The gyratory compaction method was employed in accordance with EN 12697-31 [57].

3 The current PG-4 [1] indicates that CIR laboratory specimens should be compacted 4 using this procedure. A gyratory compactor (Figure $2 \mathrm{~b}$ ) with an internal rotation angle 5 of $0.82^{\circ}$, a speed of $30 \mathrm{rpm}$, and a compaction pressure of $600 \mathrm{kPa}$ was used.

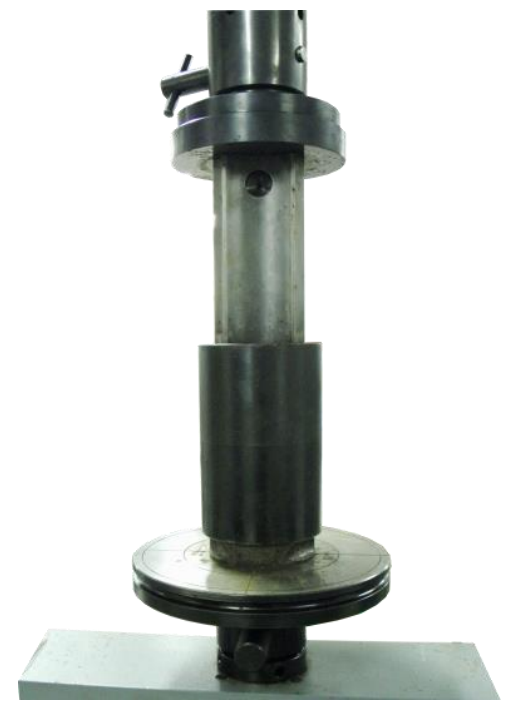

a)

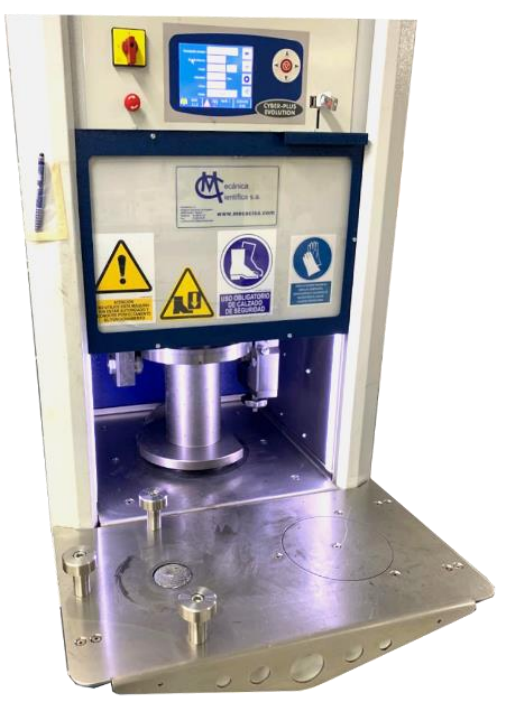

b)

Figure 2 - Compaction equipment: a) static compactor; b) gyratory compactor

In this study, five groups of cylindrical specimens (diameter of $100 \mathrm{~mm}$ and height of 65 $\pm 2 \mathrm{~mm}$ ) were designed. According to the current PG-4 specifications [1], type RE2 CIR mixtures (Figure 1) with 100-mm-inner diameter moulds should be compacted with 100 gyrations. Thus, the first gyratory group (GG1) was designed by closely following the current PG-4 specifications [1]. Different contents of bitumen emulsion were analysed (Table 4).

For the remaining studied gyratory groups (GG2, GG3, GG4, and GG5), the design parameters of the current PG-4 standard were modified to evaluate the sensitivity of the mixtures to these parameters and to see their influence on the strength results obtained, with the aim of enhancing them. The following modifications were made.
(1) The AWC was modified.
(2) The number of compaction gyrations was increased.
(3) Portland cement was added as a filler.

Concerning the AWC, as previously mentioned, the related technical literature recommends using the formulation from Equation 1. Thus, in GG2, GG3, GG4, and GG5, this formulation was used instead of that specified in the current PG-4 standard (Equation 2). Consequently, a lower AWC was tested in these groups (Table 4).

To analyse the effects of the number of gyrations on the strength and volumetric properties, 150 and 200 gyrations were employed for GG3 and GG4, respectively (Table 4).

As previously mentioned, to improve the adhesion and strength of the mixtures, the current PG-4 [1] specifications allow for the addition of up to $1.00 \%$ Portland cement. Thus, an additional $1.00 \%$ of added Portland cement was included in GG5 as a filler (Table 4). 


\begin{tabular}{|c|c|c|c|c|c|c|}
\hline Group Name & $\begin{array}{c}\text { № of } \\
\text { gyrations }\end{array}$ & BC & EC & AWC & $\begin{array}{c}\text { Portland } \\
\text { Cement }\end{array}$ & $\begin{array}{c}\text { № of } \\
\text { specimens }\end{array}$ \\
\hline \multirow{5}{*}{$\begin{array}{c}\text { Gyratory } \\
\text { group } 1 \\
\text { (GG1) }\end{array}$} & & $2.50 \%$ & $4.17 \%$ & $2.75 \%$ & \multirow{5}{*}{$0.00 \%$} & 10 \\
\hline & & $3.00 \%$ & $5.00 \%$ & 〜 $2.25 \%$ & & 10 \\
\hline & 100 & $3.50 \%$ & $5.83 \%$ & б $1.75 \%$ & & 10 \\
\hline & & $4.00 \%$ & $6.67 \%$ & Ш $1.25 \%$ & & 10 \\
\hline & & $5.25 \%$ & $8.75 \%$ & $0.00 \%$ & & 10 \\
\hline \multirow{4}{*}{$\begin{array}{c}\text { Gyratory } \\
\text { group 2 } \\
\text { (GG2) }\end{array}$} & & $1.50 \%$ & $2.50 \%$ & $2.75 \%$ & \multirow{4}{*}{$0.00 \%$} & 10 \\
\hline & 100 & $2.00 \%$ & $3.33 \%$ & $1.92 \%$ & & 10 \\
\hline & 100 & $2.50 \%$ & $4.17 \%$ & 亗 $1.08 \%$ & & 10 \\
\hline & & $3.00 \%$ & $5.00 \%$ & $0.25 \%$ & & 10 \\
\hline \multirow{4}{*}{$\begin{array}{c}\text { Gyratory } \\
\text { group } 3 \\
\text { (GG3) }\end{array}$} & & $1.50 \%$ & $2.50 \%$ & $2.75 \%$ & \multirow{4}{*}{$0.00 \%$} & 10 \\
\hline & 150 & $2.00 \%$ & $3.33 \%$ & ᄃ $1.92 \%$ & & 10 \\
\hline & 150 & $2.50 \%$ & $4.17 \%$ & $\overline{\dot{\Psi}} 1.08 \%$ & & 10 \\
\hline & & $3.00 \%$ & $5.00 \%$ & $0.25 \%$ & & 10 \\
\hline \multirow{4}{*}{$\begin{array}{c}\text { Gyratory } \\
\text { group } 4 \\
\text { (GG4) }\end{array}$} & \multirow{4}{*}{200} & $1.50 \%$ & $2.50 \%$ & $2.75 \%$ & \multirow{4}{*}{$0.00 \%$} & 10 \\
\hline & & $2.00 \%$ & $3.33 \%$ & - $1.92 \%$ & & 10 \\
\hline & & $2.50 \%$ & $4.17 \%$ & யَ 1.08\% & & 10 \\
\hline & & $3.00 \%$ & $5.00 \%$ & $0.25 \%$ & & 10 \\
\hline \multirow{5}{*}{$\begin{array}{c}\text { Gyratory } \\
\text { group } 5 \\
\text { (GG5) }\end{array}$} & & $1.50 \%$ & $2.50 \%$ & $5.00 \%$ & \multirow{4}{*}{$1.00 \%$} & 10 \\
\hline & 100 & $2.00 \%$ & $3.33 \%$ & - $4.17 \%$ & & 10 \\
\hline & 100 & $2.50 \%$ & $4.17 \%$ & 崩 3.33\% & & 10 \\
\hline & & $3.00 \%$ & $5.00 \%$ & $2.50 \%$ & & 10 \\
\hline & & & & & Total & 210 \\
\hline
\end{tabular}

18

Table 4 - Design parameters of the gyratory groups

\subsubsection{Strength and water sensitivity tests}

In accordance with the former PG-4 [45] and the standard NLT-162 [61], five series of 10 cylindrical specimens each were manufactured (Table 3 ) and compacted via static compaction (Figure 2a). Once the compaction of the specimens was complete, they were cured in an oven at $50{ }^{\circ} \mathrm{C}$ for $3 \mathrm{~d}$. In each series, five specimens were conditioned according to the Spanish immersion-compression standard NLT-162 [61], by submerging the specimens in water at $60 \pm 1^{\circ} \mathrm{C}$ (wet group), while five specimens were placed in a chamber at $25 \pm 1{ }^{\circ} \mathrm{C}$ (dry group). In both cases, the specimens were conditioned over a period of $1 \mathrm{~d}$. Before being tested (Figure $3 \mathrm{a}$ ), all the specimens were submerged in water at $25 \pm 1 \stackrel{\circ}{ } \mathrm{C}$ over a period of $120 \mathrm{~min}$.

The retained strength ratio (RSR) was calculated as follows:

$$
\operatorname{RSR}(\%)=\frac{U C S_{w e t}}{U C S_{d r y}} \cdot 100
$$

Equation 3

where $U C S_{\text {wet }}$ and $U C S_{\text {dry }}$ represent the average unconfined compressive strengths (UCSs) of the samples in the wet and dry groups, respectively. The minimum requirements of the former PG-4 for the UCS (obtained according to NLT-161 [55], as shown in Figure 3a) and RSR are presented in Table 5.

\begin{tabular}{l|ccc} 
Heavy traffic categories $^{*}$ & UCS $_{\text {dry }}$ (MPa) & UCS $_{\text {wet }}$ (MPa) & RSR (\%) \\
\hline T1 (base) and T2 & 3.00 & 2.50 & 75 \\
T3, T4, and shoulders & 2.50 & 2.00 & 70
\end{tabular}

*Traffic category T1 refers to $2000>$ annual average daily heavy traffic (AADHT) $\geq 800$; traffic category T2 refers to $800>A A D H T \geq 200$; traffic category $T 3$ refers to $200>$ AADHT $\geq 50$; traffic category 74 refers to AADHT $<50$.

Table 5 - Minimum requirements for the immersion-compression test based on the former PG-4 
Additionally, in accordance with the current PG-4 [1], 21 gyratory series of 10 cylindrical specimens each were manufactured (Table 4) and compacted via gyratory compaction (Figure 2b). The compaction process followed the standard EN 12697-31 [57]. Again, the specimens were cured in an oven at $50{ }^{\circ} \mathrm{C}$ for $3 \mathrm{~d}$ and then properly conditioned before being tested. To this end, five of the specimens in each series comprised the "wet group" and were conditioned via application of a vacuum for $30 \pm 5$ min and immersion in water at $40 \pm 1{ }^{\circ} \mathrm{C}$ for $70 \mathrm{~h}$, in accordance with EN 12697-12 [63]. The other five specimens comprised the "dry group" and were kept at room temperature $(20 \pm 5 \stackrel{\circ}{\circ})$. Finally, before being tested (Figure $3 b$ ), all the specimens were kept in a climatic chamber at $15^{\circ} \mathrm{C}$ for $150 \mathrm{~min}$.

11 The ITS ratio (ITSR) was calculated as follows:

$$
\operatorname{ITSR}(\%)=\frac{I T S_{w e t}}{I T S_{d r y}} \cdot 100
$$

Equation 4

where ITS wet $_{\text {represents the average ITS of the samples in the wet group, and ITS }}$ dry represents the average ITS of the samples in the dry group. The current PG-4 standard [1] specifies minimum values for the ITS, which is determined according to EN 1269723 [62] (Figure 3b), and ITSR, as shown in Table 6.

\begin{tabular}{l|ccc} 
Heavy traffic categories $^{*}$ & ITS $_{\text {dry }}$ (MPa) & ITS $_{\text {wet }}$ (MPa) & ITSR (\%) \\
\hline T1 (base) and T2 & 1.70 & 1.30 & 75 \\
T3, T4, and shoulders & 1.20 & 0.90 & 70
\end{tabular}

*Traffic category T1 refers to $2000>$ AADHT $\geq 800$; traffic category T2 refers to $800>$ AADHT $\geq 200$; traffic category T3 refers to $200>A A D H T \geq 50$; traffic category T4 refers to AADHT $<50$.

Table 6 - Minimum requirements for the ITS test based on the current PG-4

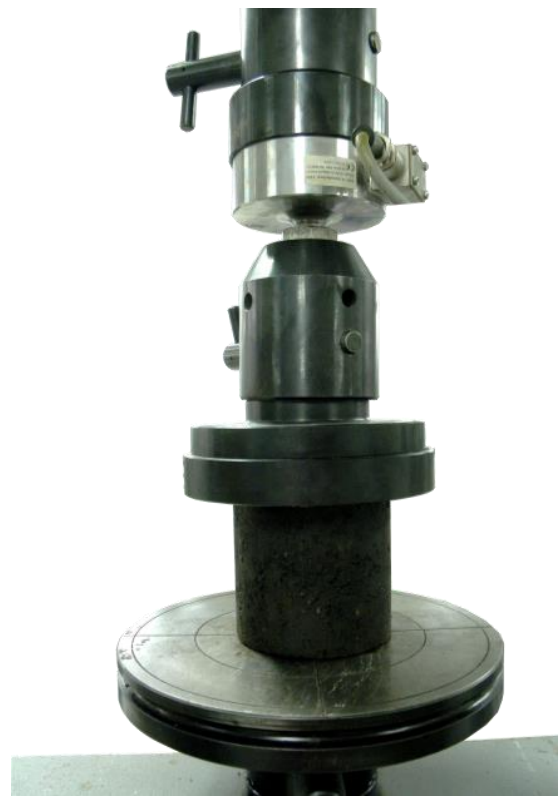

a)

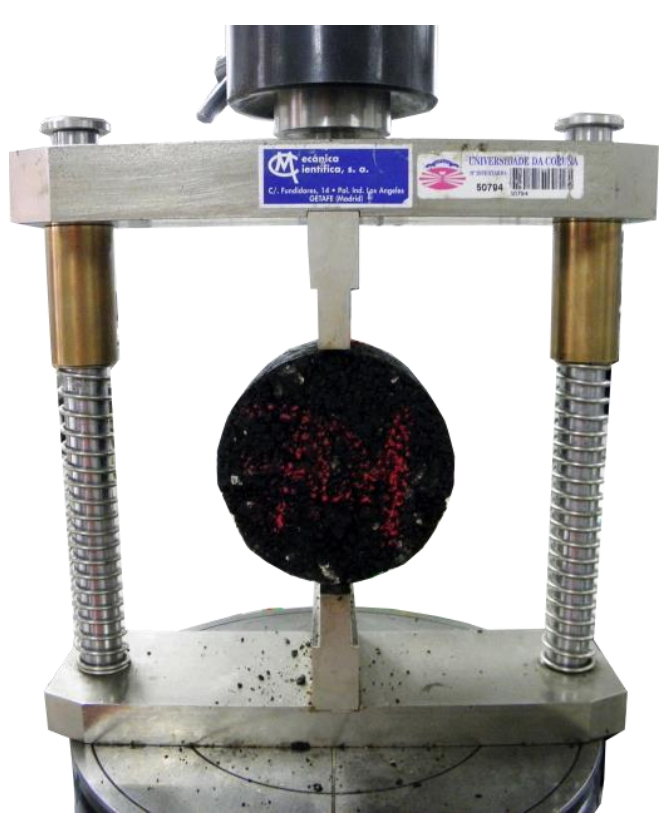

b)

Figure 3 - Strength testing equipment: a) UCS; b) ITS 
2 Immediately after compaction and prior to testing, the specimens of all the groups were 3 unmoulded, weighed, and cured in an oven at $50{ }^{\circ} \mathrm{C}$ for $3 \mathrm{~d}$ [1]. Immediately after the 4 curing, the bulk specific density was calculated using the saturated surface dry (SSD) 5 method described in EN 12697-6 [58], and the air-void content was determined in 6 accordance with EN 12697-8 [59] for comparing the degrees of compaction of the 7 manufactured specimens. The following equation was used to calculate the air-void 8 content:

$$
V_{a}(\%)=\frac{\rho_{m}-\rho_{b}}{\rho_{m}} \cdot 100,
$$

Equation 5

where $V_{a}$ represents the air-void content (\%); $\rho_{m}$ represents the maximum specific density $\left(\mathrm{kg} / \mathrm{m}^{3}\right)$, which is determined according to the standard EN-12697-5 [60]; and $\rho_{b}$ represents the bulk specific density $\left(\mathrm{kg} / \mathrm{m}^{3}\right)$. As previously mentioned, the air-void content is not typically addressed in the regulations.

14 The evolution of the density over time is not considered. The density is calculated only 15 after the curing period; thus, it is assumed that the water in the mixture evaporates completely. 


\section{Results and discussion}

\subsection{Aggregate coating tests}

Two mixing times were used for the tests. First, the RAP and added water were mixed for $60 \mathrm{~s}$. Then, the bituminous emulsion was added and mixed for an additional mixing time. For mixing time 1, the bitumen emulsion was mixed for an additional $60 \mathrm{~s}$ (Figures 4 and 6). For mixing time 2, the bitumen emulsion was mixed for an additional $90 \mathrm{~s}$ (Figures 5 and 7).

Four different contents of residual binder $(1.50 \%, 2.00 \%, 2.50 \%$, and $3.00 \%)$ were tested, and their corresponding AWCs were calculated using Equation 1 (2.75\%, $1.92 \%, 1.08 \%$, and $0.25 \%$, respectively). Figures $4-7$ show the samples after mixing times 1 and 2. From left to right, the photographs are ordered from the lowest $B C$ to the highest BC (from $1.50 \%$ to $3.00 \%$ ). Figures 4 and 5 show the samples immediately after the mixing, and Figures 6 and 7 show the samples after curing for $3 d$ at $50{ }^{\circ} \mathrm{C}$.

The desired bitumen-aggregate coating was visually determined. In the case of mixing time 1, there were RAP pieces that were not properly coated, and the most uniform coating was achieved when mixing time 2 was employed. Thus, mixing time 2 was selected for the manufacturing of all the tested CIR mixtures.
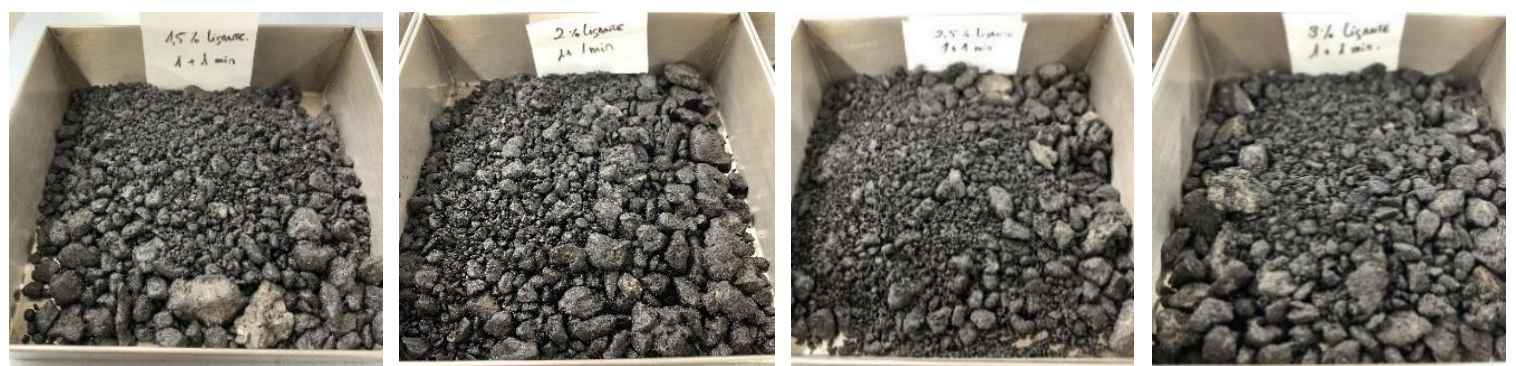

Figure 4 - Visual analysis of samples immediately after blending using mixing time 1
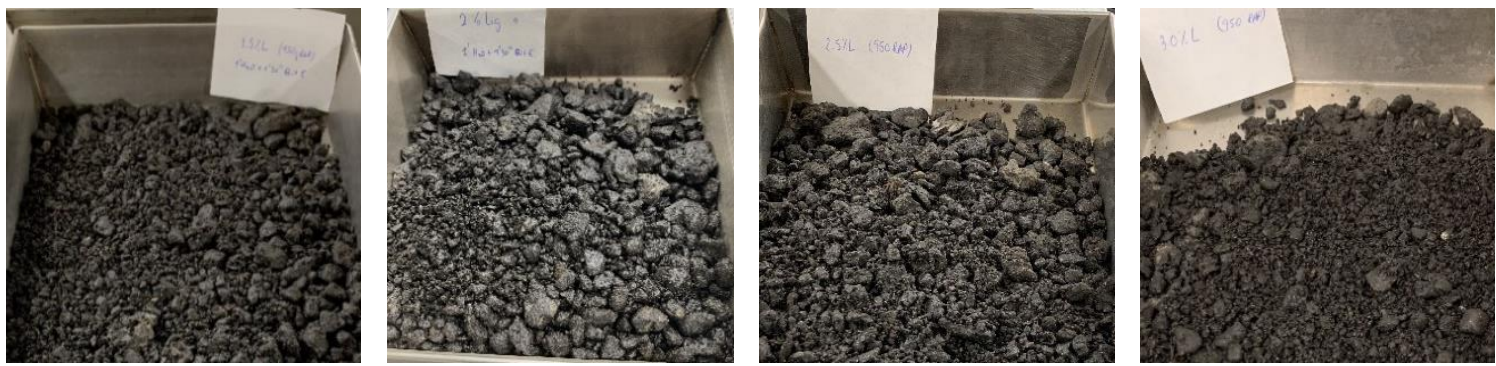

Figure 5 - Visual analysis of samples immediately after blending using mixing time 2
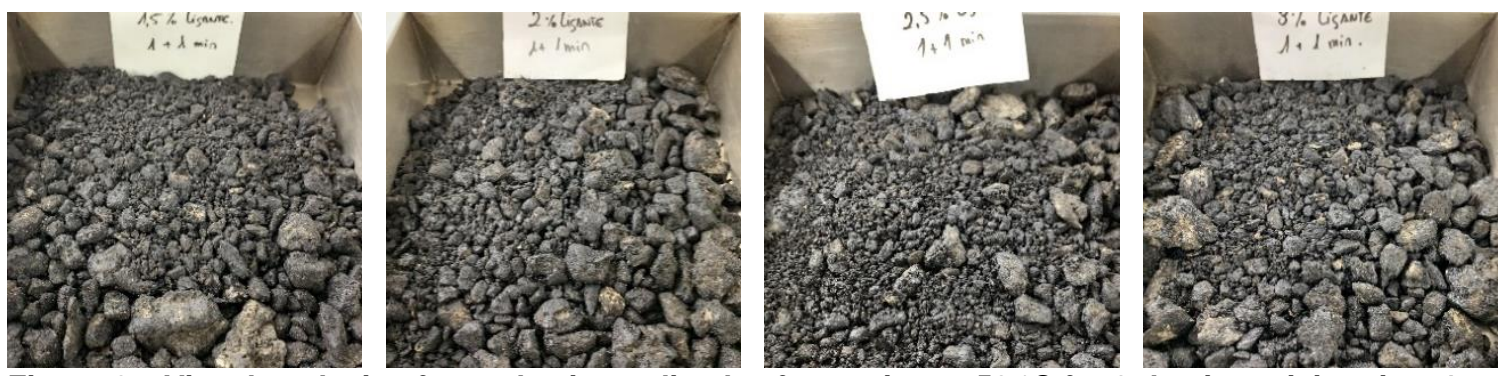

Figure 6 - Visual analysis of samples immediately after curing at $50^{\circ} \mathrm{C}$ for $3 \mathrm{~d}$ using mixing time 1 

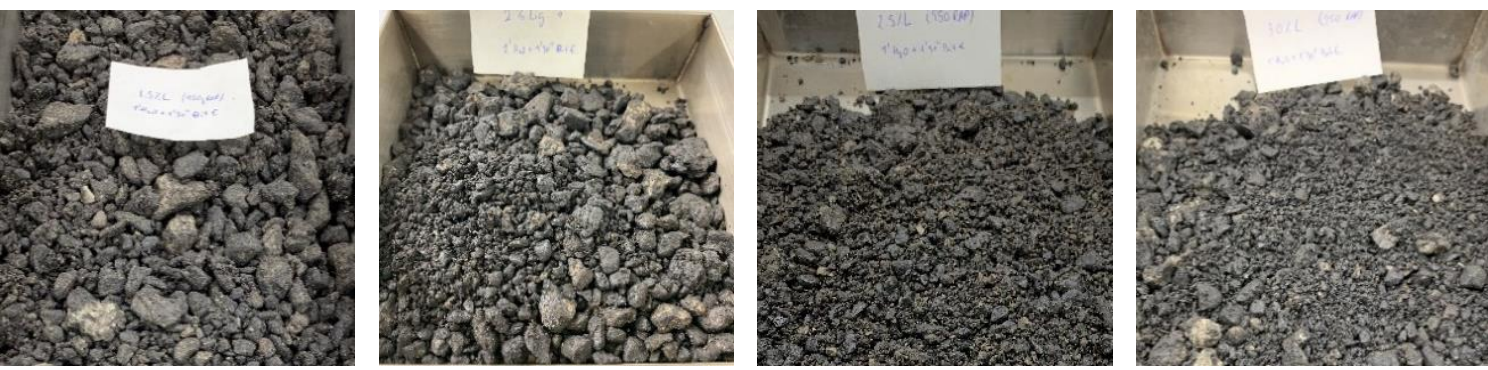

Figure 7 - Visual analysis of samples immediately after curing at $50{ }^{\circ} \mathrm{C}$ for $3 \mathrm{~d}$ using mixing time 2

\subsection{OFC and Modified Proctor test}

The results of the Modified Proctor test are presented in Figure 8. When this test was performed with $100 \%$ of the RAP, a maximum dry density of $1.94 \mathrm{~g} / \mathrm{cm}^{3}$ was achieved at an OFC of $5.75 \%$. When $1.00 \%$ Portland cement was added to the RAP, a dry density of $2.00 \mathrm{~g} / \mathrm{cm}^{3}$ was achieved at an OFC of $8.00 \%$. Hence, these OFC percentages were used to calculate the AWC, in accordance with Equations 1 and 2, for each of the CIR groups. The obtained AWC values, along with the corresponding contents of BC, EC, and Portland cement, are presented in Tables 3 and 4.

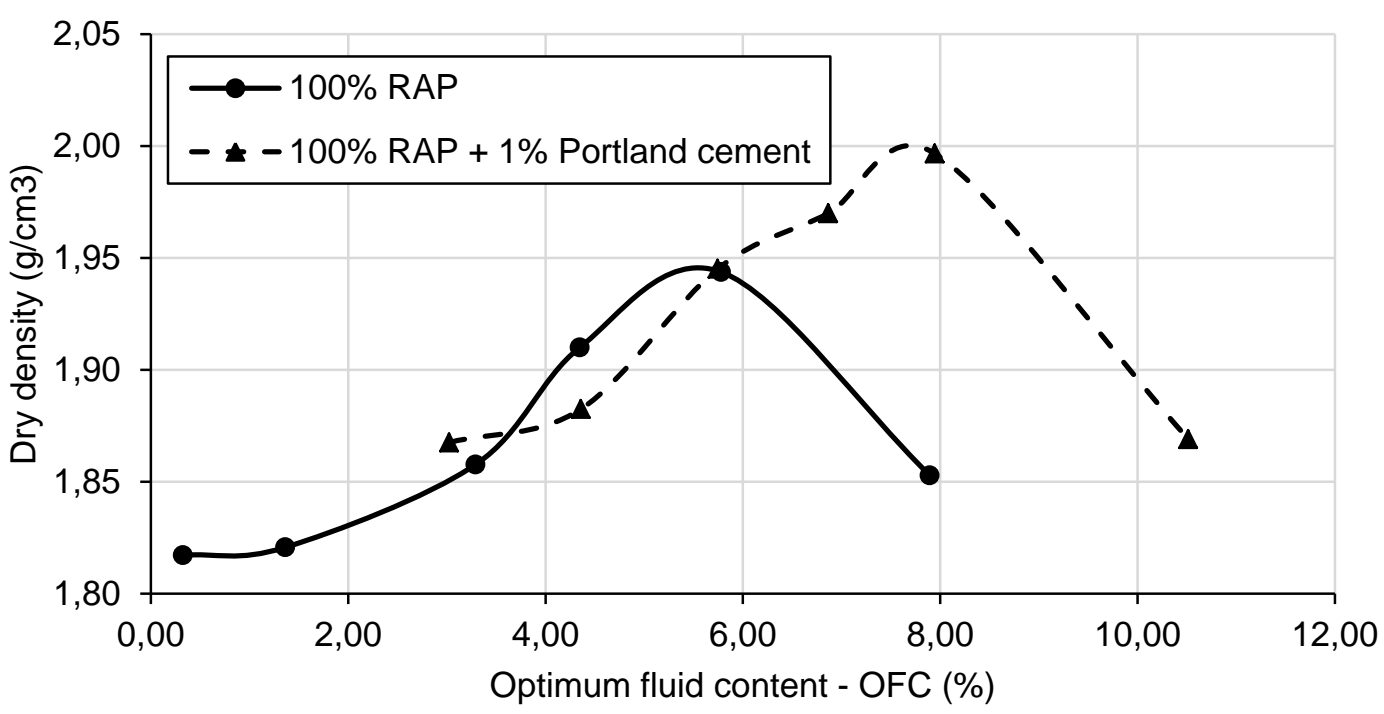

Figure 8 - Modified Proctor Test results for 100\% RAP and 100\% RAP + 1\% Portland cement

\subsection{Strength and water sensitivity test}

\subsubsection{UCS test}

As previously mentioned, the former PG-4 standard [45] specifies minimum values of the UCS and RSR for both dry and wet samples of CIR mixtures (Table 5). These minimum values are indicated by horizontal lines in Figure 9.

As previously mentioned, $50 \mathrm{CIR}$ specimens were manufactured according to the former PG-4 specifications [45]. The contents of the bitumen emulsion and added water for the different series are presented in Table 3 . The average results for UCS $S_{d r y}$ and $U C S_{\text {wet }}$ (as well as their standard deviations), along with the RSR, obtained for the five SGs are presented in Figure 9. The degree of dispersion of the results was low, confirming their validity. 


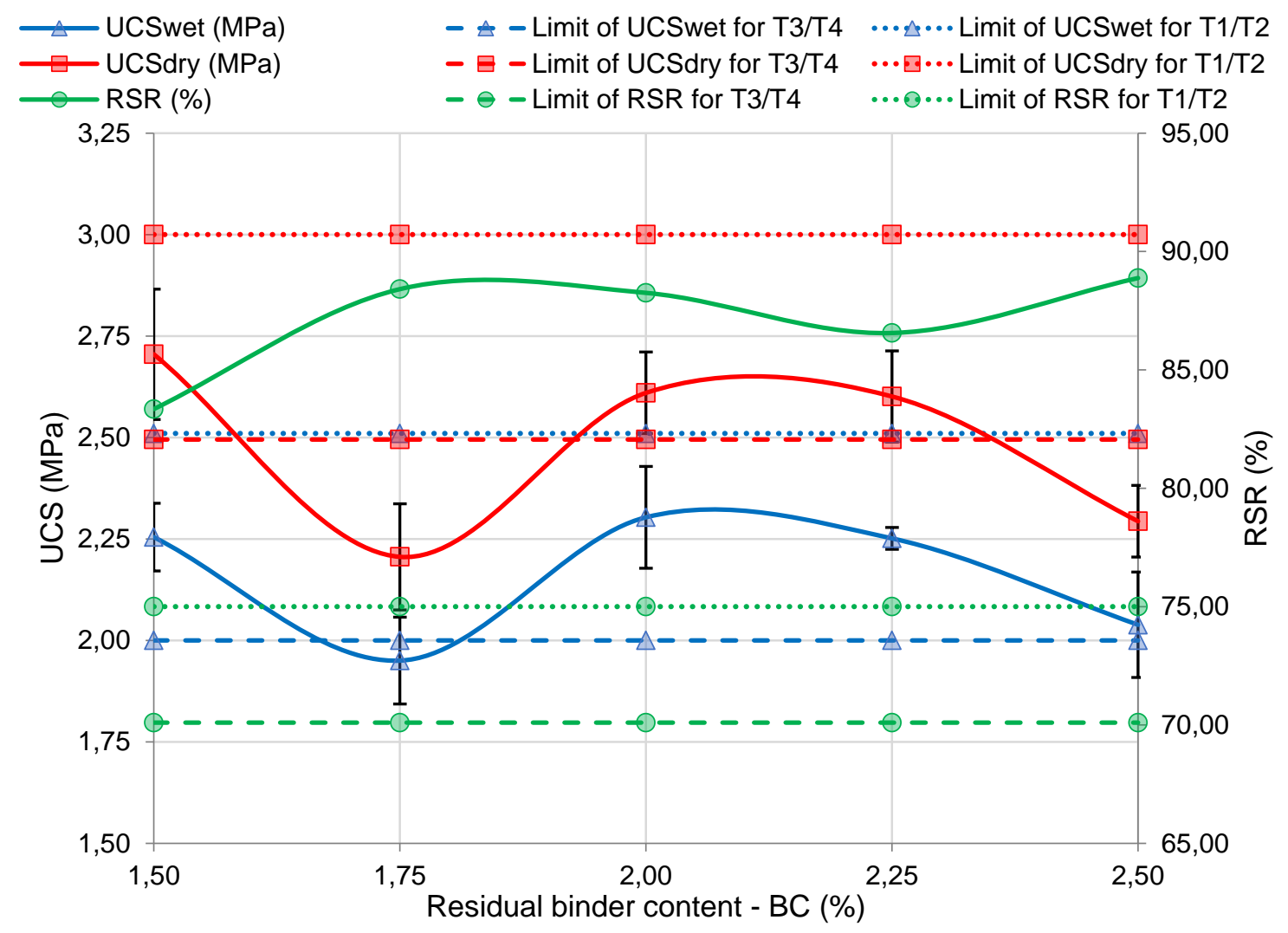

Figure 9 - UCSwet, UCSdry, and RSR results for the SGs

As shown in Figure 9, the RSR was higher than the lower limits specified by the former PG-4 specifications [45] for all the traffic categories and all the tested series. However, the $U C S_{\text {wet }}$ and $U C S_{\text {dry }}$ results satisfied the requirements only for the lower-traffic categories T3 and T4. Compliance was achieved for BCs of $1.50 \%, 2.00 \%$, and $2.25 \%$. For this reason (and in view of the highest results for the RSR), the optimum BC selected according to this method was $2.00 \%$, which corresponded to an AWC of $1.92 \%$.

The minimum required UCS values of the former PG-4 standard (Table 5) are slightly lower than those specified in the French technical guidelines for the design of CIR for the Duriez compression test. In this case, for mixtures with $>90 \%$ RAP, the minimum dry compressive strength required after $14 \mathrm{~d}$ is $4 \mathrm{MPa}$, with a RSR of at least $70 \%$.

\subsubsection{ITS test}

As previously mentioned, $210 \mathrm{CIR}$ specimens with different contents of residual binder, added water, and Portland cement (Table 4) were manufactured and compacted using a gyratory compactor (Figure $2 \mathrm{~b}$ ).

Gyratory group 1 (GG1)

As previously mentioned, the current PG-4 standard specifies minimum values of the ITS and ITSR for both dry and wet samples of CIR mixtures (Table 6). These minimum values are indicated by horizontal lines in Figure 10.

Gyratory group 1 (GG1) was manufactured according to the current PG-4 specification (Table 4). As the RAP utilised was classified as RE2, 100 gyrations of the compactor were executed (Table 4). The average results for ITS $S_{\text {dry }}$ and ITS wet (as well as their standard deviations) and the ITSR obtained for GG1 are shown in Figure 10. The standard deviation of the results was small; thus, the results had a low degree of dispersion. 


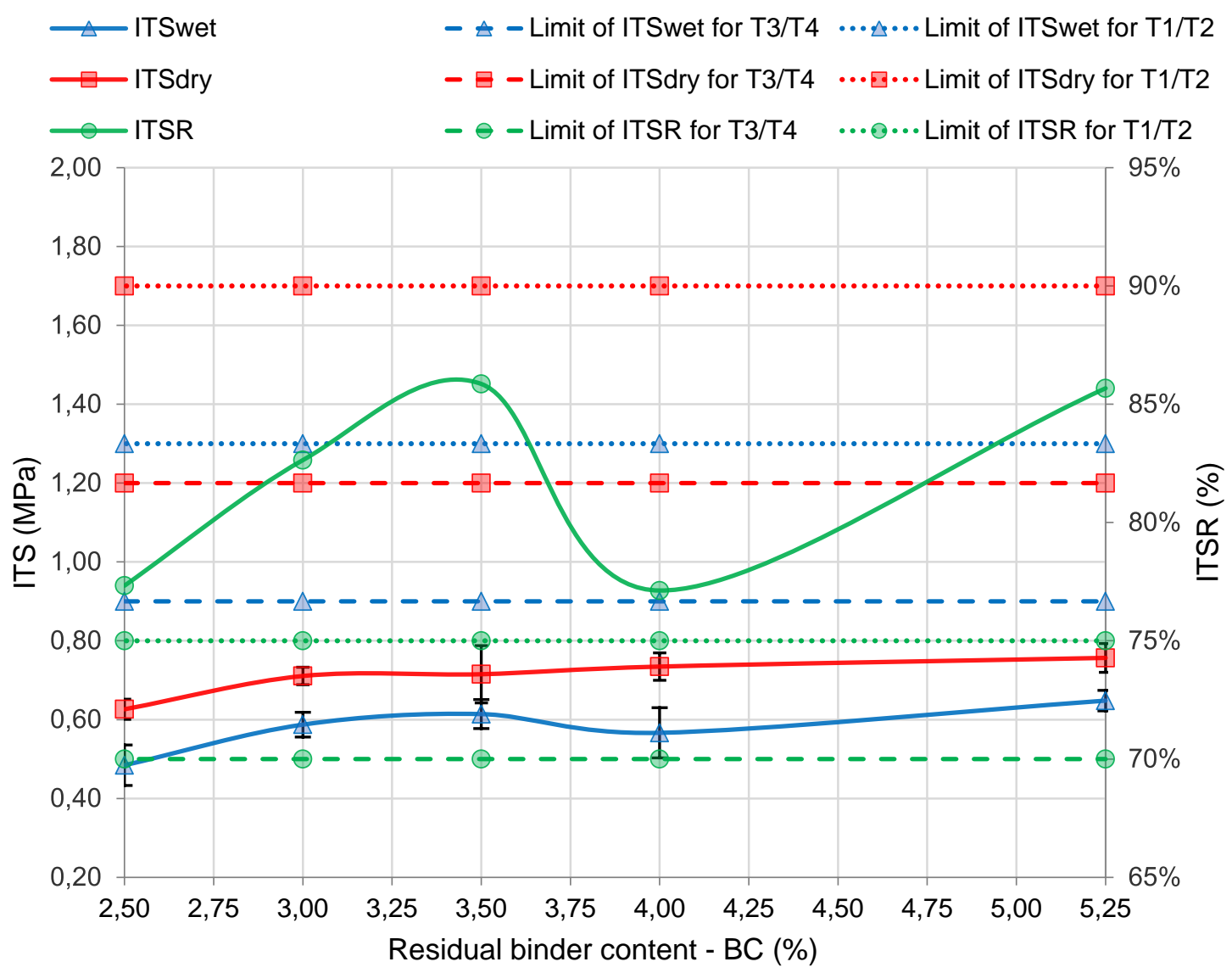

Figure 10 - ITS $S_{d r y}$, ITS $S_{\text {wet }}$, and ITSR results for GG1

3 As shown in Figure 10, the ITSR results were satisfactory in all cases and complied 4 with the lower limits of the current PG-4 specifications [1] for all traffic categories. 5 Nevertheless, the required ITS values were not achieved with either the dry or wet 6 specimen groups for any of the traffic categories. Even when the BC was increased to $75.25 \%$, these values were not reached. This small improvement in the ITS results 8 despite the large increase in the BC may have been due to the softness of the residual 9 bitumen in the emulsion (penetration rate of $170 \mathrm{dmm}$ ). The use of an emulsion with a 10 harder residual bitumen should be investigated in future studies to examine its effect on 11 the strength.

12 In contrast to the results obtained using the method recommended by the former PG-4 standard [45], the results obtained using the design method from the current PG-4 standard [1] failed to satisfy the required strength values. The mixtures were expected to satisfy the requirements of traffic categories T3 and T4 in the current specification, similar to the case of the former PG-4 standard. Thus, to comply at least with the lower limit of traffic categories T3 and T4 of the ITS dry for all the specimen series in GG1, this lower limit should be reduced by $36.67 \%-47.50 \%$ (Table 7 ), while the $I T S_{\text {wet }}$ lower limit (traffic categories T3/T4) should be reduced by $27.78 \%-46.67 \%$ (Table 7 ). The necessary reductions in the ITS requirements are presented in Table 7 for each specimen series in GG1. 


\begin{tabular}{ccccccc}
\cline { 2 - 7 } & \multicolumn{3}{c}{ ITS $_{\text {dry }}(\mathrm{MPa})$} & \multicolumn{3}{c}{ ITS $_{\text {wet }}(\mathrm{MPa})$} \\
\hline BC (\%) & Test result & Lower limit & Reduced by & Test result & Lower limit & Reduced by \\
\hline 2.50 & 0.63 & 1.20 & $47.50 \%$ & 0.48 & 0.90 & $46.67 \%$ \\
3.00 & 0.71 & 1.20 & $40.83 \%$ & 0.59 & 0.90 & $34.44 \%$ \\
3.50 & 0.72 & 1.20 & $40.00 \%$ & 0.61 & 0.90 & $32.22 \%$ \\
4.00 & 0.73 & 1.20 & $39.17 \%$ & 0.57 & 0.90 & $36.67 \%$ \\
5.25 & 0.76 & 1.20 & $36.67 \%$ & 0.65 & 0.90 & $27.78 \%$ \\
\hline
\end{tabular}

Table 7 - Required reductions in the lower limits of the ITS from PG-4 according to the GG1 results

As indicated by Table 7 , for this particular case, a reduction of approximately $40 \%$ in the required ITS values would cause almost all the specimens series in GG1 (except those with a BC of $2.50 \%$ ) to satisfy the required lower limits for at least the lowertraffic categories T3 and T4.

The required ITS values in the current PG-4 standard (Table 6) are significantly higher than those in other technical guidelines and manuals. Thus, ARRA CR201 (Annapolis, 2016) [44] and a recent NCAT study (Auburn University) published in AASHTO PP 94 (2018) [65] indicate that CIR specimens compacted using either a gyratory compactor with 30 gyrations or a Marshall hammer with 75 blows per side should satisfy the minimum ITS dry requirement of $0.31 \mathrm{MPa}$ (45 psi) and the minimum ITSR requirement of $60 \%-70 \%$.

Design manuals for CIR mixtures such as Wirtgen's (Germany, 2012) [27] and Shatec Engineering's (California, 2013) [28] are also based on the gyratory compactor and specify ITS dry and ITS wet requirements. The Wirtgen Manual indicates that the gyratory compaction employed should achieve the same density as $100 \%$ Marshall Compaction, and the Shatec Manual specifies that 25 gyrations should be used. Thus, the required $I T S_{\text {dry }}$ values are 0.225 and $0.25 \mathrm{MPa}$, respectively, and the required ITS wet values are 0.10 and $0.23 \mathrm{MPa}$, respectively.

Concerning the origin of these ITS requirements in the current PG-4 standard, the background studies that led to the development and establishment of these limits are unknown. In view of the foregoing discussion and the results obtained, it can be concluded that a reduction in the lower limits of ITS $S_{d r y}$ and ITS $S_{\text {wet }}$ of the current Spanish specification is justified and necessary. However, the proposed limit adjustment (reduction of $40 \%$ of $I T S_{d r y}$ and $I T S_{\text {wet }}$ requirements) is based on results for mixtures manufactured using particular types of RAP and bitumen emulsion. To correctly make decisions and suggest more reliable strength requirements, a more comprehensive study should be conducted.

With the suggested reduction of at least $40 \%$, both lower limits of the ITS would be closer to those specified in other countries but would still be more than double or triple the values recommended by other road agencies and guidelines. They are likely to remain too high and require further reduction. With regard to the ITRS requirements, in view of the compliance of the different studied groups, it is considered appropriate to maintain the current values.

In conclusion, it is considered that this study is among the group of studies contributing to the consistent correction of the current Spanish specification for the CIR.

\section{Gyratory groups 2, 3, 4, and 5 (GG2, GG3, GG4, and GG5)}

For the remaining gyratory groups, three modifications were considered to evaluate the sensitivity of the ITS results and increase them: a reduction in the AWC, an increase in the number of gyrations of the compactor, and the addition of Portland cement as a filler. 
Equation 1 was used to determine the AWCs of GG2, GG3, GG4, and GG5 (Table 4). These groups were tested and compared with the results of GG1. We also attempted to improve the compaction by increasing the number of gyrations from 100 to 150 and 200, for GG3 and GG4, respectively. Finally, 1.00\% Portland cement was added as a filler (relative to the weight of the RAP) to GG5 (using the same number of gyrations and added-water formulation as GG2). Therefore, GG2, GG3, GG4, and GG5 did not fully comply with the manufacturing specifications of the current PG-4 standard.

8 The average results for ITS dry and ITS wet (as well as their standard deviations), along 9 with the ITSRs obtained for GG2, GG3, GG4, and GG5, are presented in the bar 10 graphs of Figure 11. Additionally, the lower limits of ITS $S_{d r y}$, ITS $S_{\text {wet, }}$ and ITSR for traffic 11 categories T1/T2 and T3/T4 are indicated by horizontal lines in Figure 11.
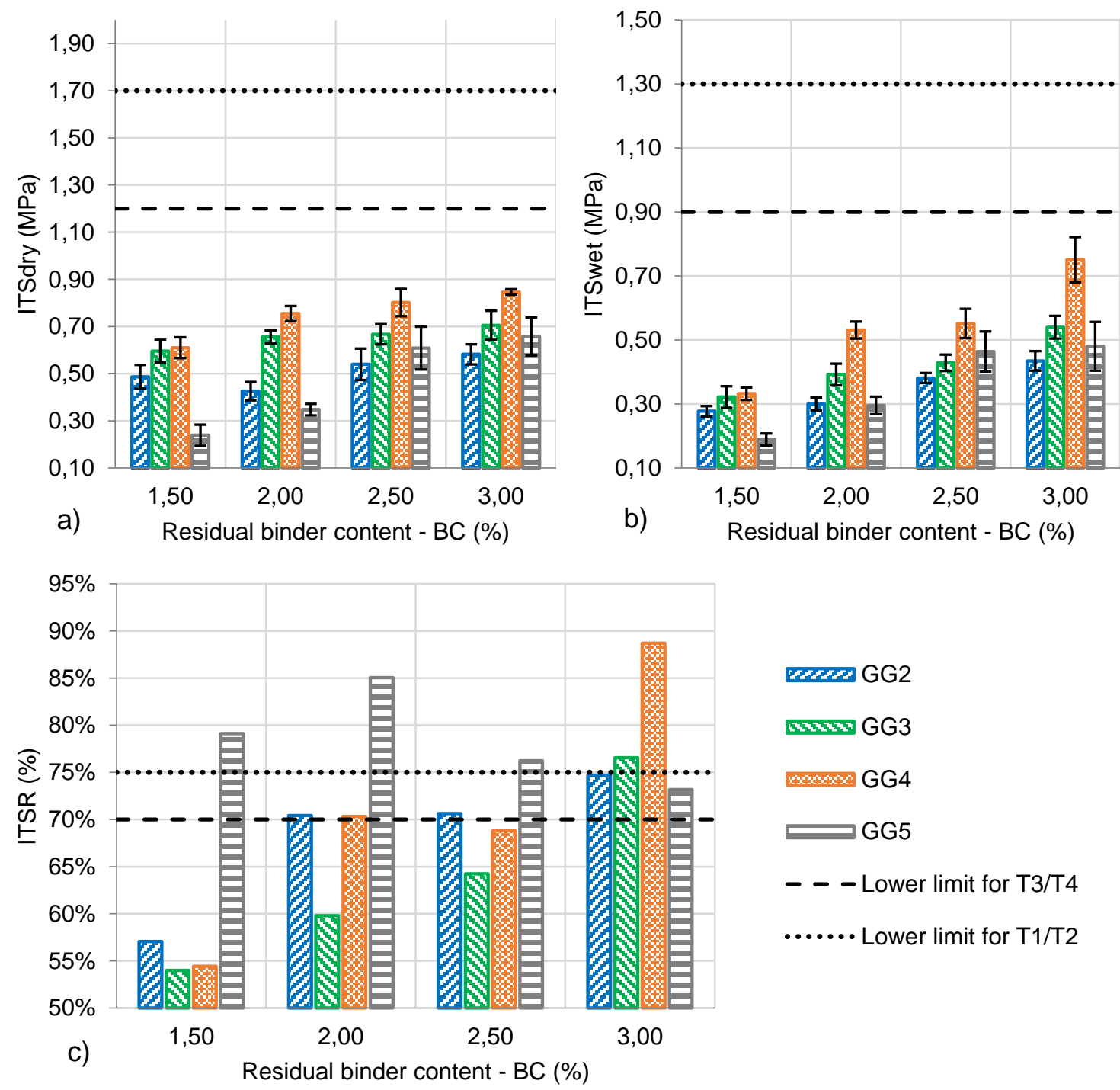

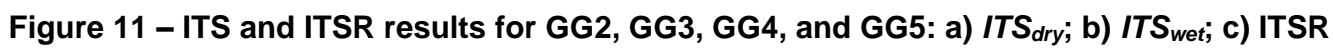

As shown in Figures $11 \mathrm{a}$ and $11 \mathrm{~b}$, the minimum required $I T S_{d r y}$ and $I T S_{\text {wet }}$ values were not achieved for any of the tested specimens (even for $2.00 \% \mathrm{BC}$ and $1.92 \%$ AWC, which were identified as the optimum contents by the former PG-4 standard). As for the other groups, the dispersion of the results was small; thus, an adequate level of repeatability is assumed.

These figures also indicate that with the increasing BC, the ITS increased. However, this enhancement was insufficient to satisfy the requirements. An increase in the 
number of gyrations from 100 to 150 and then to 200 (corresponding to GG2, GG3, and GG4, respectively) led to an increase in the ITS, as expected. This increase ranged from $15.89 \%$ to $77.22 \%$, depending on the $\mathrm{BC}$.

4 Even the addition of Portland cement (GG5) did not result in a satisfactory outcome.

5 Compared with GG2, GG5 exhibited reductions of $1.48 \%-50.86 \%$ in the $I T S_{d r y}$ and $6 I_{\text {ITet }}$ for the lowest BCs (1.50\% and 2.00\%). However, for the highest BCs $(2.50 \%$ 7 and $3.00 \%$ ), the $I T S_{d r y}$ and $I T S_{w e t}$ values increased by $44.81 \%-72.77 \%$. These 8 increments were insufficient to achieve compliance with the current Spanish 9 specifications (Figures 11a and 11b).

10 Regarding the ITSR (Figure 11c), it was determined that higher levels of compaction (i.e. larger number of gyrations) and higher BCs were associated with higher ITSR values. Thus, the only specimen series from GG2 and GG3 that satisfied the lower limits of the ITSR for traffic categories T3 and T4 were those with the highest BC (i.e. $3.00 \%$ ). In the case of GG4, the specimens with BCs of $2.50 \%$ and $3.00 \%$ satisfied the required lower limit for traffic categories T3 and T4. Furthermore, GG5, which included $1.00 \%$ Portland cement and had the highest ITSR value among all the groups, satisfied the lower limits for all traffic categories, except when the BC was maximised. A likely reason for this reduction in the ITSR of the GG5 was the deficit of water, as the AWC was the lowest for the series with the highest BC.

The hydration process of Portland cement involves many different reactions that require several days to be completed (at least $7 \mathrm{~d}$ to develop most of the early strength). Therefore, the lack of added water in mix series with higher BCs, combined with the accelerated curing process, did not allow the cement in the GG5 specimens to properly hydrate. Because of the poor hydration of the cement, its strength did not develop properly; thus, the GG5 specimens did not behave as expected. The behaviour of these mixtures was not improved as intended and was sometimes even worsened. Thus, if cement is added to the studied mixtures, the use of an accelerated curing process at such a high temperature $\left(50^{\circ} \mathrm{C}\right)$ is not recommended (if the curing is performed, it should follow a longer waiting period and at a lower temperature).

As shown in Figure 11, a BC of $3.00 \%$ led to the highest $I T S_{d r y}$, ITS $S_{\text {wet, }}$ and ITSR values for all the gyratory groups that did not include cement.

The compaction energy significantly affected the $I T S_{d r y}$ and $I T S_{\text {wet }}$ results. Although the increase in the number of compaction gyrations was insufficient to satisfy the requirements of the current PG-4, it led to a significant increase in the strength. The average $I T S_{d r y}$ increased by $22.50 \%$ and $32.50 \%$ when the number of compaction gyrations increased from 100 to 150 and 200, respectively. Relative to the average

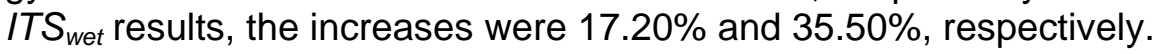

38 Comparison of groups compacted with 100 gyrations (GG1, GG2, and GG5)

A comparison of the average ITS values obtained for GG1, GG2, and GG5 (Figure 12) led to interesting results, as these three groups were each compacted with 100 gyrations.

42 The GG1 specimens had the highest AWC, as they were designed according to the 43 current PG-4 specifications (Equation 2). For GG2 and GG5, the added-water groups had lower AWCs than GG1. The GG5 specimens differed from the GG2 specimens in that they contained $1.00 \%$ Portland cement. 

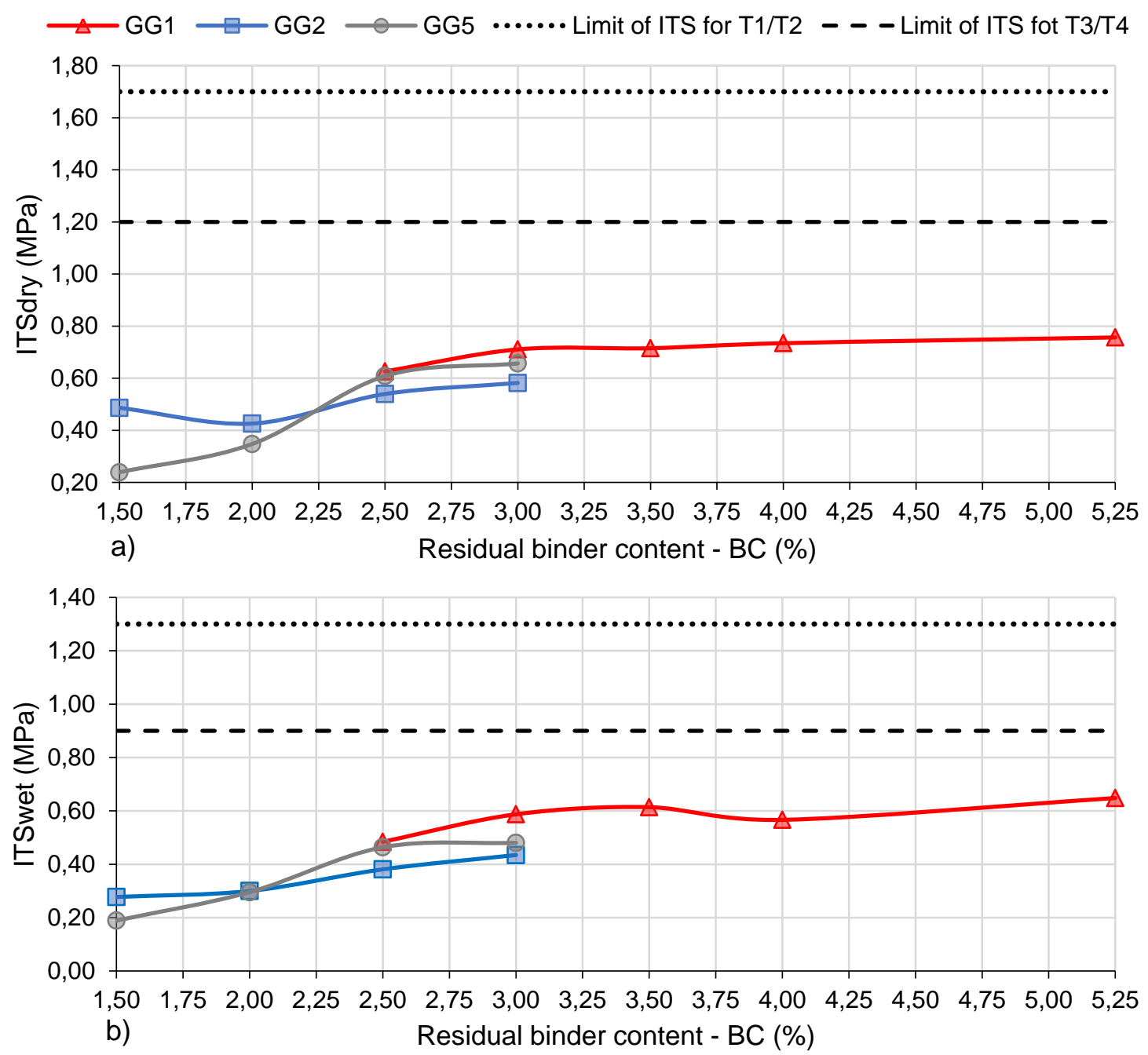

Figure 12 - ITS results for the gyratory groups compacted with 100 gyrations: a) ITS dry; b) ITS wet

As shown in Figure 12, for BCs of $2.50 \%$ and $3.00 \%$ (the common values of the residual binder content for the three compared groups), the ITS values were the highest for GG1, as these specimens had the highest AWCs. Thus, by reducing the AWC, the ITS dry values were reduced by $13.86 \%-18.13 \%$, and the $I T S_{\text {wet }}$ values were reduced by $21.34 \%-25.99 \%$. It is concluded that a high AWC is beneficial and makes essential contributions in the initial stages of mixing and compaction, improving the ITS.

As shown in Figures 11a and 11b, a comparison of GG2 and GG5 revealed that the addition of $1.00 \%$ of Portland cement to the GG5 specimens as a filler reduced the ITS values obtained for the lowest $B C s$ and increased the ITS values obtained for the highest BCs. As mentioned previously, this reduction in the ITS results for GG5 may have been due to the lack of added water for these specimens. Additionally, the accelerated curing process of the specimens prevented the proper hydration of the cement; thus, its resistance was not fully developed.

Similar to the case of Figure 10, the lines in Figure 12 indicate that the ITS did not increase significantly as the $\mathrm{BC}$ increased, resulting in a flat shape. As previously mentioned, one of the reasons for this behaviour is that the residual binder in the bitumen emulsion was too soft. 
2 Table 11 presents the air-void contents and average bulk densities obtained for each 3 group, as well as the standard deviations $\left(S_{r}\right)$ of the densities. It also shows the 4 residual binder, added water, and Portland cement contents employed for each group.

\begin{tabular}{|c|c|c|c|c|c|c|c|}
\hline $\begin{array}{l}\text { Group } \\
\text { Name }\end{array}$ & $B C$ & & AWC & $\begin{array}{l}\text { Portland } \\
\text { Cement }\end{array}$ & Air Voids & $\begin{array}{c}\text { Bulk } \\
\text { Density } \\
\left(\mathrm{kg} / \mathrm{m}^{3}\right)\end{array}$ & $\begin{array}{l}S_{r} \text { Bulk } \\
\text { Density } \\
\left(\mathrm{kg} / \mathrm{m}^{3}\right)\end{array}$ \\
\hline \multirow{5}{*}{$\begin{array}{l}\text { Static group } \\
\quad(\mathrm{SG})\end{array}$} & $1.50 \%$ & & $2.75 \%$ & \multirow{5}{*}{$0.00 \%$} & $8.14 \%$ & 2232.28 & 5.42 \\
\hline & $1.75 \%$ & - & $2.33 \%$ & & $8.00 \%$ & 2235.71 & 3.81 \\
\hline & $2.00 \%$ & $\bar{\sigma}$ & $1.92 \%$ & & $7.42 \%$ & 2242.53 & 4.73 \\
\hline & $2.25 \%$ & & $1.50 \%$ & & $7.45 \%$ & 2241.82 & 10.27 \\
\hline & $2.50 \%$ & & $1.08 \%$ & & $6.44 \%$ & 2240.16 & 3.35 \\
\hline \multirow{5}{*}{$\begin{array}{c}\text { Gyratory } \\
\text { group } 1 \\
\text { (GG1) }\end{array}$} & $2.50 \%$ & & $2.75 \%$ & \multirow{5}{*}{$0.00 \%$} & $14.33 \%$ & 2041.10 & 16.95 \\
\hline & $3.00 \%$ & $N$ & $2.25 \%$ & & $13.80 \%$ & 2053.52 & 15.75 \\
\hline & $3.50 \%$ & $\dot{\sigma}$ & $1.75 \%$ & & $13.32 \%$ & 2065.16 & 15.87 \\
\hline & $4.00 \%$ & & $1.25 \%$ & & $12.93 \%$ & 2074.40 & 5.69 \\
\hline & $5.25 \%$ & & $0.00 \%$ & & $12.35 \%$ & 2088.17 & 11.65 \\
\hline \multirow{4}{*}{$\begin{array}{c}\text { Gyratory } \\
\text { group 2 } \\
\text { (GG2) }\end{array}$} & $1.50 \%$ & & $2.75 \%$ & \multirow{4}{*}{$0.00 \%$} & $15.51 \%$ & 2057.72 & 11.61 \\
\hline & $2.00 \%$ & $\tau$ & $1.92 \%$ & & $15.01 \%$ & 2055.98 & 14.45 \\
\hline & $2.50 \%$ & $\dot{\dot{ய ்}}$ & $1.08 \%$ & & $14.58 \%$ & 2056.99 & 29.88 \\
\hline & $3.00 \%$ & & $0.25 \%$ & & $12.75 \%$ & 2078.55 & 6.29 \\
\hline \multirow{4}{*}{$\begin{array}{c}\text { Gyratory } \\
\text { group } 3 \\
\text { (GG3) }\end{array}$} & $1.50 \%$ & & $2.75 \%$ & \multirow{4}{*}{$0.00 \%$} & $15.81 \%$ & 2061.74 & 4.98 \\
\hline & $2.00 \%$ & $\tau$ & $1.92 \%$ & & $14.96 \%$ & 2057.39 & 9.40 \\
\hline & $2.50 \%$ & $\dot{\dot{ய}}$ & $1.08 \%$ & & $14.54 \%$ & 2067.47 & 11.70 \\
\hline & $3.00 \%$ & & $0.25 \%$ & & $12.59 \%$ & 2080.37 & 28.30 \\
\hline \multirow{4}{*}{$\begin{array}{c}\text { Gyratory } \\
\text { group } 4 \\
\text { (GG4) }\end{array}$} & $1.50 \%$ & & $2.75 \%$ & \multirow{4}{*}{$0.00 \%$} & $14.53 \%$ & 2081.58 & 24.91 \\
\hline & $2.00 \%$ & - & $1.92 \%$ & & $14.42 \%$ & 2070.42 & 14.54 \\
\hline & $2.50 \%$ & ச் & $1.08 \%$ & & $13.21 \%$ & 2078.22 & 14.46 \\
\hline & $3.00 \%$ & & $0.25 \%$ & & $12.54 \%$ & 2083.73 & 20.18 \\
\hline \multirow{4}{*}{$\begin{array}{c}\text { Gyratory } \\
\text { group } 5 \\
\text { (GG5) }\end{array}$} & $1.50 \%$ & & $5.00 \%$ & \multirow{4}{*}{$1.00 \%$} & $15.43 \%$ & 2053.98 & 30.27 \\
\hline & $2.00 \%$ & - & $4.17 \%$ & & $16.65 \%$ & 2021.53 & 9.36 \\
\hline & $2.50 \%$ & ச் & $3.33 \%$ & & $13.97 \%$ & 2056.53 & 13.73 \\
\hline & $3.00 \%$ & & $2.50 \%$ & & $13.68 \%$ & 2058.76 & 9.04 \\
\hline
\end{tabular}

Table 11 - Bulk densities and air-void contents of the studied series

Regarding the volumetric properties, the static compaction was stronger than the gyratory compaction and significantly increased the bulk density and reduced the airvoid content for the SG specimens. By analysing the values in Table 11, series with the same BCs and AWCs were compared. For the series with a BC of $2.50 \%$ and an AWC of $1.08 \%$ in GG2 and SG, the average bulk density was 2056.99 and $2240.16 \mathrm{~kg} / \mathrm{m}^{3}$, respectively. Thus, it increased by $8.90 \%$, which is substantial.

Similarly, increasing the number of gyrations (GG2, GG3, and GG4) increased the bulk density. However, this increase was practically insignificant. For the series with a BC of $2.50 \%$ and an AWC of $1.08 \%$ in GG2 and GG4, the bulk density was 2056.99 and $2078.22 \mathrm{~kg} / \mathrm{m}^{3}$, respectively. In this case, increasing the number of gyrations from 100 to 200 was inefficient; it increased the average bulk density by only $0.78 \%$ while doubling the compaction energy used.

18 As previously mentioned, typical values of the density of CIR mixtures after good 19 compaction in the field are approximately $2000-2100 \mathrm{~kg} / \mathrm{m}^{3}$. In this regard, compared 20 with static compaction, gyratory compaction with 100 gyrations provided laboratory 
estimations closer to the compaction that is achieved in the field. All the bulk-density results obtained for the gyratory groups were within the aforementioned range, whereas the bulk-density results for the $S G$ exceeded $2230 \mathrm{~kg} / \mathrm{m}^{3}$ in all cases. Therefore, the static compaction described in the former PG-4 standard is considered to be excessive for the representation of field compaction, and use of the gyratorycompaction specified in the current PG-4 standard is recommended.

The SSD method employed is not the most suitable technique for CIR mixtures owing to the high void content. Because of this (along with the high heterogeneity of the RAP), the bulk-density results may not be as reliable as desired. In future volumetric studies, methods that are more suitable for porous mixtures should be used, such as the sealed specimen method, which is described in EN 12697-6 [58]. It is noteworthy that the Sr of bulk density measurements were lower for static compacted specimens than for those compacted with gyratory (since static is a more powerful compaction)

\section{Conclusions and recommendations}

CIR mixtures were manufactured using two design methods. The differences between the methods included the type of compaction (static vs. gyratory), AWC formulation, and mechanical strength and water sensitivity tests required (UCS vs. ITS). Additionally, the effects of the addition of Portland cement and the compaction energy were examined. The resulting strengths were evaluated and compared with the requirements from different specifications.

As a result, the following conclusions and recommendations were drawn:

1) Regarding the former PG-4 specification, the specimens with BCs of $1.50 \%$, $2.00 \%$, and $2.25 \%$ satisfied the UCS and RSR requirements for lower-traffic categories T3 and T4. According to this design method, the optimum BC is $2.00 \%$, corresponding to an AWC of $1.92 \%$.

2) With regard to the current PG-4 specification (GG1), the manufactured specimens did not satisfy the minimum ITS. Even so, the highest ITS values were achieved for the highest BCs studied $(3.00 \% \mathrm{BC})$. The ITSR results satisfied the requirements.

3) To comply with the strength requirements of the current PG-4 standard, for the CIR mixtures designed in accordance with these specifications (i.e. GG1), it was found that the lower limits of the ITS should be reduced by at least $40 \%$. This reduction is supported by the requirements of other specifications and manuals, as well as by the lack of background studies on the current requirements. However, for establishing a more appropriate correction of the ITS $S_{\text {dry }}$ and ITS wet requirements from the Spanish specifications, deeper investigation is needed. Regarding the limits of the ITSR, it is recommended to maintain the minimum values specified in the current PG-4 standard.

4) Reducing the AWC reduced the ITS. A higher AWC was found to be beneficial and mainly affected the mixing and compaction stages. Thus, use of the formulation in the current PG-4 specification (Equation 2) is recommended. Additionally, in future studies, mixtures with higher AWCs should be tested in light of the results presented herein and the water contents employed in other CIR design methods; thus, the optimal AWC should be identified.

5) Static compaction significantly increased the bulk density compared with gyratory compaction. However, the static compaction conducted in this study (pressure of $21 \mathrm{MPa}$ for $2 \mathrm{~min}$ ) was considered excessive, as it produced specimens with densities significantly higher than those attained in the field. Gyratory compaction is more suitable, as it better represents the field compaction. Therefore, it is recommended that gyratory compaction be retained in the current specification. The static compaction method can be suitable for reducing the pressure or compaction time to weaken the compaction. 
6) An increase in the number of gyrations from 100 to 200 led to a significant increase in the average ITS (from $15.89 \%$ to $77.22 \%$, depending on the mix series), but the requirements were not satisfied. Although the compaction energy was doubled, the increase in the density was $<1 \%$. Thus, increasing the number of gyrations is considered to be inefficient, and the use of 100 gyrations is recommended (in accordance with the current PG-4 standard), as long as the current ITS requirements have been reviewed.

7) Adding $1.00 \%$ of Portland cement (by weight of RAP) to the mixtures as a filler reduced the ITS for the lowest BCs studied (1.50\% and $2.00 \%)$. However, the ITS values increased for the highest BCs (2.50\% and $3.00 \%)$. Considering the cost associated with adding Portland cement and the fact that the minimum ITS values were not reached, the addition of Portland cement is recommended only for high BCs and when strictly necessary.

8) Regarding the manufacturing of CIR with the addition of Portland cement, the lack of added water in the series with higher BC and the accelerated curing of the specimens interfered with the hydration of the cement; thus, the strength of the cement was not fully developed. It is therefore proposed that the specimens of this type of mixture should be cured under more convenient temperature and humidity conditions. 


\section{Acknowledgements}

The authors would like to acknowledge the funding of project BIA2016-80317R/AEI/10.13039/501100011033 by the Spanish Ministry of Economy and Competitiveness with an associated pre-doctoral scholarship for research worker training (FPI) BES-2017-079633. The authors also would like to express their sincere gratitude to ARIAS INFRAESTRUCTURAS for the RAP and to CEPSA and ECOASFALT for the bitumen emulsion, which was generously donated for this study.

\section{References}

[1] Ministry of Development (2017) Recycling of bituminous pavements and roadways. Circular Order 40/2017. In Spanish.

[2] Nivedya, M. K., \& Veeraragavan, A. (2017). Bitumen-stabilised materials for sustainable road infrastructure. Sustainability Issues in Civil Engineering (pp. 3550). Springer, Singapore. https://doi.org/10.1007/978-981-10-1930-2_3

[3] Niazi, Y., \& Jalili, M. (2009). Effect of Portland cement and lime additives on properties of cold in-place recycled mixtures with asphalt emulsion. Construction and Building Materials, 23(3), 1338-1343. https://doi.org/10.1016/j.conbuildmat.2008.07.020

[4] Carter, A., Feisthauer, B., Lacroix, D., \& Perraton, D. (2010). Comparison of cold in-place recycling and full-depth reclamation materials (No. 10-1325).

[5] Behnood, A., Gharehveran, M. M., Asl, F. G., \& Ameri, M. (2015). Effects of copper slag and recycled concrete aggregate on the properties of CIR mixes with bitumen emulsion, rice husk ash, Portland cement and fly ash. Construction and Building Materials, 96, 172-180. https://doi.org/10.1016/j.conbuildmat.2015.08.021

[6] Lin, J., Huo, L., Xu, F., Xiao, Y., \& Hong, J. (2018). Development of microstructure and early-stage strength for $100 \%$ cold recycled asphalt mixture treated with emulsion and cement. Construction and Building Materials, 189, 924-933. https://doi.org/10.1016/j.conbuildmat.2018.09.064

[7] Xiao, F., Yao, S., Wang, J., Li, X., \& Amirkhanian, S. (2018). A literature review on cold recycling technology of asphalt pavement. Construction and Building Materials, 180, 579-604. https://doi.org/10.1016/j.conbuildmat.2018.06.006

[8] Pakes, A., Edil, T., Sanger, M., Olley, R., \& Klink, T. (2018). Environmental Benefits of Cold-in-Place Recycling. Transportation Research Record, 2672(24), 11-19. https://doi.org/10.1177/0361198118758691

[9] Gu, F., Ma, W., West, R. C., Taylor, A. J., \& Zhang, Y. (2019). Structural performance and sustainability assessment of cold central-plant and in-place recycled asphalt pavements: A case study. Journal of cleaner production, 208, 1513-1523. https://doi.org/10.1016/j.jclepro.2018.10.222

[10] Valdes-Vidal, G., Calabi-Floody, A., \& Sanchez-Alonso, E. (2018). Performance evaluation of warm mix asphalt involving natural zeolite and reclaimed asphalt pavement (RAP) for sustainable pavement construction. Construction and Building Materials, 174, 576-585. https://doi.org/10.1016/j.conbuildmat.2018.04.149

[11] Park, K., Hwang, Y., Seo, S., \& Seo, H. (2003). Quantitative assessment of environmental impacts on life cycle of highways. Journal of construction engineering and management, 129(1), 25-31.

[12] Wang, T., Xiao, F., Zhu, X., Huang, B., Wang, J., \& Amirkhanian, S. (2018). Energy consumption and environmental impact of rubberized asphalt pavement. Journal of cleaner production, 180, 139-158. https://doi.org/10.1016/j.jclepro.2018.01.086

[13] Nättorp, A., Dinkel, F., \& Zschokke, M. (2019). Environmental impact of biogenic oils as raw materials in road construction. International Journal of Pavement Engineering, 20(6), 714-723. https://doi.org/10.1080/10298436.2017.1330080 
[14] Pérez, I., Medina, L., \& del Val, M. Á. (2013). Mechanical properties and behaviour of in situ materials which are stabilised with bitumen emulsion. Road Materials and Pavement Design, 14(2), 221-238. https://doi.org/10.1080/14680629.2013.779301

[15] Kim, Y., Im, S., \& Lee, H. D. (2010). Impacts of curing time and moisture content on engineering properties of cold in-place recycling mixtures using foamed or emulsified asphalt. Journal of Materials in Civil Engineering, 23(5), 542-553. https://doi.org/10.1061/\%28ASCE\%29MT.1943-5533.0000209

[16] Graziani, A., lafelice, C., Raschia, S., Perraton, D., \& Carter, A. (2018). A procedure for characterizing the curing process of cold recycled bitumen emulsion mixtures. Construction and Building Materials, 173, 754-762. https://doi.org/10.1016/j.conbuildmat.2018.04.091

[17] Raschia, S., Perraton, D., Graziani, A., \& Carter, A. (2020). Influence of low production temperatures on compactability and mechanical properties of cold recycled mixtures. Construction and Building Materials, 232, 117169. https://doi.org/10.1016/j.conbuildmat.2019.117169

[18] Dolzycki, B., Jaczewski, M., \& Szydlowski, C. (2017). The long-term properties of mineral-cement-emulsion mixtures. Construction and Building Materials, 156, 799808. https://doi.org/10.1016/j.conbuildmat.2017.09.032

[19] Modarres, A., Rahimzadeh, M., \& Zarrabi, M. (2014). Field investigation of pavement rehabilitation utilizing cold in-place recycling. Resources, Conservation and Recycling, 83, 112-120. https://doi.org/10.1016/j.resconrec.2013.12.011

[20] Wood, L. E., White, T. D., \& Nelson, T. B. (1988). Current practice of cold in-place recycling of asphalt pavements. Transportation Research Record, (1178).

[21] Bazrafshan Moghadam, B., \& Farhad Mollashahi, H. (2017). Suggesting a simple design method for cold recycled asphalt mixes with asphalt emulsion. Journal of Civil Engineering and Management, 23(7), 966-976. https://doi.org/10.3846/13923730.2017.1343200

[22] Tebaldi, G., Dave, E., Hugener, M., Falchetto, A. C., Perraton, D., Grilli, A. \& Apeagyei, A. (2018). Cold recycling of reclaimed asphalt pavements. Testing and Characterization of Sustainable Innovative Bituminous Materials and Systems (pp. 239-296). Springer, Cham. https://doi.org/10.1007/978-3-319-71023-5_6

[23] AASHTO-AGC-ARTBA Joint Cooperation Committee, \& AASHTO-AGC-ARTBA Joint Cooperation Committee. Task Force No. (1998). Report on cold recycling of asphalt pavements. American Association of State Highway and Transportation Officials.

[24] Manual, B. A. R. (2001). Asphalt Recycling and Reclaiming Association (ARRA). Annapolis, Md, 225-226.

[25] Jenkins, K. J., \& Twagira, M. E. (2008). Updating Bituminous Stabilized Materials Guidelines: Mix Design Report, Phase II. Technical Memorandum.

[26] Kim, Y., \& Lee, H. D. (2006). Development of mix design procedure for cold inplace recycling with foamed asphalt. Journal of Materials in Civil Engineering, 18(1), 116-124. https://doi.org/10.1061/(ASCE)08991561(2006)18:1(116)

[27] Wirtgen. (2012). Cold recycling technology. Germany.

[28] Shatec Engineering Consultants, LLC (2013). Cold in-place recycling with expanded asphalt mix (CIR EAM/FOAM) technology. California.

[29] Mollenhauer, K., \& Gaspar, L. (2012). Synthesis of European knowledge on asphalt recycling: options, best practices and research needs. SYNTHESIS, 5, 472.

[30] Dołżycki, B., \& Jaskuła, P. (2019). Review and evaluation of cold recycling with bitumen emulsion and cement for rehabilitation of old pavements. Journal of Traffic and Transportation Engineering (English Edition). https://doi.org/10.1016/j.jtte.2019.02.002

[31] Mollenhauer, K., Simnofske, D., Valentin, J., Čížková, Z., Suda, J., Batista, F., \& McNally, C. (2016) Mix designs for cold recycled pavement materials considering 
local weather and traffic conditions. 6th Eurasphalt \& Eurobitume Congress. 1-3 June 2016. Prague, Czech Republic.

[32] Association Mondiale de la Route (AIPCR) and World Road Association (PIARC). (2003). Pavement recycling. Guidelines for in-place recycling with cement, in-place recycling with emulsion or foamed bitumen, hot mix recycling in plant. La Defense Cedex, France.

[33] CFTR - SETRA. Technical Guide - Cold in-place recycling of old pavements. (2003). In French.

[34] F. Batista, J. Valentin, Z. Čížková, T. Valentová, D. Simnofske, K. Mollenhauer, A. Tabakovic, C. McNally, M. Engels. CEDR Transnational Road Research Programme, Call 2012: Recycling: Road Construction in a Post-fossil Fuel Society. Report on available test and mix design procedures for cold-recycled bitumen stabilised materials.

[35] Asphalt Academy. (2009). Technical guideline No.2: Bitumen stabilised materials. A guideline for the design and construction of bitumen emulsion and foamed bitumen stabilised materials. Pretoria, South Africa.

[36] Gandi, A., Cardenas, A., Sow, D., Carter, A., \& Perraton, D. (2019). Study of the impact of the compaction and curing temperature on the behavior of cold bituminous recycled materials. Journal of Traffic and Transportation Engineering (English Edition), 6(4), 349-358.

[37] Consuegra, A. E., Little, D. N., Von Quintus, H., \& Burati, J. (1988). Comparative evaluation of laboratory compaction devices based on their ability to produce mixtures with engineering properties similar to those produced in the field (Master's thesis, Texas A\&M University).

[38] Sufian, Z., Matori, M. Y., \& Hussain, M. Z. (2008). Mix design for cold-in-place pavement recycling; does it guarantee performance? In Proceedings of the 3rd European Pavement \& Asset Management Conference (EPAM3) 7-9 July 2008, Coimbra, Portugal.

[39] Radzi, H. M., Muniandy, R., Hassim, S., Law, T. H., \& Jakarni, F. M. (2019, April). An overview of asphalt mix designs using various compactors. In IOP Conference Series: Materials Science and Engineering (Vol. 512, No. 1, p. 012031). IOP Publishing. https://doi.org/10.1088/1757-899X/512/1/012031

[40] Sebaaly, P. E., Castro, J., Hajj, E., \& Center, W. R. S. (2018). Development of InPlace Density Method for Cold In-Place Recycling (No. WRSC-UNR-UTC-CIR-1). University of Nevada, Reno. Solaris University Transportation Center.

[41] Cross, S. A. (2003). Determination of Superpave® gyratory compactor design compactive effort for cold in-place recycled mixtures. Transportation research record, 1819(1), 152-160.

[42] Martínez, A. H., Miró, R., \& Pérez-Jiménez, F. (2007). Spanish experience with gyratory compactor and indirect tensile test in design and control of cold recycled asphalt pavement. Transportation research record, 2001(1), 163-168.

[43] Miro, R. (2007). Evaluación de los métodos de reciclado y rehabilitación de firmes a partir del análisis de los tramos experimentales del proyecto europeo PARAMIX. Infraestructura Vial, 110(18).

[44] CR-201 Recommended Mix Design Guidelines for Cold Recycling Using Emulsified Asphalt Recycling Agent. Asphalt Recycling \& Reclaiming Association (ARRA), Annapolis, MD. Revised 4/7/2016.

[45] Ministry of Development (2001) "Pavement recycling". Circular Order 8/2001. In Spanish

[46] AENOR, Spanish Association for Standardisation and Certification, 2012. UNE-EN 933-1 Tests to determine the geometric properties of aggregates. Part 1: Determination of particle size. Sifting method. Madrid. In Spanish

[47] AENOR, Spanish Association for Standardisation and Certification, 2006. UNE-EN 1097-6. Tests to determine the mechanical and physical properties of aggregates. Part 6: Determination of particle density and water absorption. Madrid. In Spanish 
[48] Ministry of Public Works and Transport, 1990. NLT standards. NLT-164/90. Binder content in bituminous mixtures. Road tests. Directorate General for Roads, 2nd ed. Madrid, Spain. In Spanish

[49] Ministry of Development. (2015). General technical specifications for road and bridge works (PG-3). In Spanish

[50] AENOR, Spanish Association for Standardization and Certification, 1959. UNE-EN 7151-59. Testing of aggregate coating with asphalt emulsions. Madrid. In Spanish

[51] Piratheepan, M. (2011). Designing Cold Mix Asphalt (CMA) and Cold-In-Place Recycling (CIR) Using Superpave Gyratory Compactor (Doctoral dissertation).

[52] AENOR, Spanish Association for Standardization and Certification, 1994. UNE-EN 103-501-94. Geotechnics. Compaction test. Modified Proctor. Madrid. In Spanish

[53] Martínez, A. H., Miró, R., \& Pérez-Jiménez, F. (2007). Spanish experience with gyratory compactor and indirect tensile test in design and control of cold recycled asphalt pavement. Transportation Research Record, 2001(1), 163-168. https://doi.org/10.3141/2001-18

[54] Nosetti, A., Pérez-Madrigal, D., Pérez-Jiménez, F., \& Martínez, A. H. (2018). Effect of the recycling process and binder type on bituminous mixtures with $100 \%$ reclaimed asphalt pavement. Construction and Building Materials, 167, 440-448. https://doi.org/10.3390/ma12121992

[55] Ministry of Public Works and Transport, 2002. NLT standards. NLT-161. Compressive strength of bituminous mixtures. Road test. Madrid, Spain: Center for the Study and Experimentation of Public Works (CEDEX); 2002. In Spanish

[56] French Standards Association, French standard NFP 98-251-1, Hydrocarbon asphalt mixes. Static testing of hydrocarbon mixtures. Part 1: Duriez tests on hotmix hydrocarbon mixtures, Paris, France, 2004. In French

[57] AENOR, Spanish Association for Standardization and Certification, 2008. UNE-EN 12697-31. Bituminous mixtures. Test methods for hot bituminous mixtures. Part 31: Specimen preparation by gyratory compactor. Madrid. In Spanish

[58] AENOR, Spanish Association for Standardisation and Certification, 2012. EN 12697-6. Bituminous mixtures. Test methods for hot bituminous mixtures. Part 6: Determination of apparent density of bituminous samples. Madrid. In Spanish

[59] AENOR, Spanish Association for Standardisation and Certification, 2003. UNE-EN 12697-8. Bituminous mixtures. Test methods for hot bituminous mixtures. Part 8 : Determination of voids content in bituminous samples. Madrid. In Spanish

[60] AENOR, Spanish Association for Standardisation and Certification, 2010. EN 12697-5. Bituminous mixtures. Test methods for hot bituminous mixtures. Part 5: Determination of maximum density. Madrid. In Spanish

[61] Ministry of Public Works and Transport, 2002. NLT standards. NLT-162. Effect of water on the cohesion of compacted bituminous mixtures (Immersion-compression test). Road tests. Directorate General for Roads, 2nd ed. Madrid, Spain. In Spanish

[62] AENOR, Spanish Association for Standardisation and Certification, 2017. EN 12697-23. Bituminous mixtures. Test methods. Part 23: Determination of the indirect tensile strength of bituminous specimens. Madrid. In Spanish

[63] AENOR, Spanish Association for Standardisation and Certification, 2009. EN 12697-12. Bituminous mixtures. Test methods for hot bituminous mixtures. Part 12: Determination of sensitivity to water of bituminous mixtures specimens. Madrid. In Spanish

[64] Cox, B. C., \& Howard, I. L. (2015). Cold in-place recycling characterization framework and design guidance for single or multiple component binder systems (No. FHWA/MS-DOT-RD-15-250-Volume 2).

[65] AASHTO PP 94, Standard Specification for Determination of Optimum Asphalt Content of Cold Recycled Mixture with Foamed Asphalt. American Association of State Highway and Transportation Officials, Washington, D.C., 2018. 